\title{
El fracaso de la actividad empresarial por cuenta propia. Factores regionales, macroeconómicos e institucionales*
}

\author{
Self-employed business activity failure. \\ Regional, macroeconomic and institutional factors
}

\author{
Francisco DEL OLMO GARCÍA \\ Instituto Universitario de Análisis Económico y Social \\ Universidad de Alcalá \\ Programa de Doctorando en Economía y Gestión \\ Empresarial \\ Dr. Fernando Javier CRECENTE ROMERO \\ Instituto Universitario de Análisis Económico y Social \\ Universidad de Alcalá
}

\begin{abstract}
Resumen: España es, bajo una perspectiva estructural y cultural, un país de Pymes. No cabe duda de esta afirmación cuando los datos ilustran una realidad en la que el $99,9 \%$ del tejido empresarial español está compuesto por Pymes. Sin embargo, detrás de esta realidad se esconde otra no menos importante: más del $55 \%$ de las empresas no tienen asalariados.

La importancia de los empresarios autónomos es reflejo del espíritu emprendedor que fundamenta la economía española. Sin embargo, a pesar de las numerosas medidas destinadas a fomentar el emprendimiento, no se presta suficiente atención a la sostenibilidad de dichos proyectos emprendedores, es decir, al fracaso.
\end{abstract}

\footnotetext{
* Este artículo obtuvo, el pasado curso académico 2018-2019, el Premio Reina María Cristina, en su séptima edición, en la modalidad de Economía, patrocinado por el Banco Santander. El jurado calificador estuvo formado por: $\mathrm{D}^{\mathrm{a}}$ María Begoña García Greciano (Presidenta), Decana de la Facultad de Ciencias Económicas y Empresariales de la UCM; D. Jaime Terceiro Lomba (Vocal), Catedrático de Análisis Económico, UCM.; D. ${ }^{a}$ Mónica Gómez de la Torre del Arco (Vocal), Profesora de Sistema Fiscal, RCU Escorial-María Cristina, y D. Agustín Alonso Rodríguez (Secretario), Decano de Administración y Dirección de Empresas del "Real Centro Universitario Escorial María Cristina".
} 
Bajo este contexto, el presente trabajo tiene como objetivo indagar en los principales factores que amenazan la supervivencia a un año de los empresarios autónomos. Mediante un análisis multinivel basado en los datos de la EPA, se busca, por un lado, entender los factores sociodemográficos que caracterizan a los empresarios que no han prosperado en su proyecto mientras que, por otro lado, se pretende indagar en los factores de naturaleza macroeconómica e institucional, resultando significativos el crecimiento del PIB, la tasa de desempleo, la deuda pública, la evolución del crédito la evolución de la presión fiscal, la carga regulatoria y la eficiencia del sistema judicial, todas medidas desde una perspectiva autonómica.

\begin{abstract}
Spain is, under a structural and cultural point of view, a small and medium enterprises country. In fact, available data show the $99,9 \%$ of the Spanish business structure is based on small and medium enterprises. Nevertheless, it is also very important to know that the $55 \%$ of those firms does not have any employees. Despite self-employed entrepreneurship is one the most important pillars of the Spanish economy and in spite of the importance of entrepreneurship policies, sustainability and failure of these business projects has not had enough attention.
\end{abstract}

Under this context, this paper has the aim of analyzing the main factors which conditionate the early surveillance of self-employed entrepreneurs. Through a multilevel analysis based on Labour Force Survey microdata, it is sought to understand the socioeconomic, macroeconomic and institutional factors which characterized failed self-employed business projects. To sum up, results show the following regional variables are significant factors of self-employed entrepreneurship failure: GDP growth, unemployment rate, public debt rate, banking credit and tax burden growth rate, regulatory pressure and the efficiency of the judicial system.

Palabras clave: autónomos; fracaso emprendedor; factores socioeconómicos; condicionantes institucionales; magnitudes macroeconómicas; análisis multinivel; EPA.

Keywords: self-employed entrepreneurship; business failure; socioeconomic factors, institutional conditions, macroeconomic magnitudes; multilevel analysis; Labour Force Survey

Códigos JEL: L26; R38; O17; G3 
Sumario:

I. Introducción.

II. La importancia del empresario autónomo en la economía española.

III. El fracaso del empresario autónomo en España.

IV. Hipótesis de trabajo.

4.1. Características socioeconómicas.

4.2. Condicionantes macroeconómicos.

4.3. Condicionantes institucionales.

V. Metodología.

5.1. Muestra

5.2. Regresión Logística Multinivel

VI. Definición de las variables y datos utilizados.

6.1. El fracaso emprendedor como variable dependiente.

6.2. Variables explicativas.

6.2.1. Variables representativas de las características socioeconómicas de los empresarios.

6.2.2. Variables macroeconómicas.

6.2.3. Variables macroeconómicas.

\section{Resultados.}

VIII. Discusión y conclusiones.

IX. Bibliografía. 



\section{INTRODUCCIÓN}

A lo largo de las últimas décadas, el interés mostrado por las causas del fracaso empresarial no ha hecho más que aumentar, llevando a los investigadores a profundizar en las diversas acepciones del concepto de fracaso, a ampliar el abanico de posibles factores explicativos del fenómeno y a aplicar nuevas metodologías cuantitativas que aumentaban las posibilidades predictivas (Tascón y Castaño, 2012).

No obstante, no es habitual que la literatura sobre fracaso empresarial tenga en cuenta la heterogeneidad regional que se da en muchos países y que lleva a diferencias en el entorno de las empresas. En este sentido, la estructura económica española tiene, entre otras, dos características que destacan especialmente con respecto a otros países de su entorno. Por un lado, un mayor peso de las empresas de menor tamaño, con un gran protagonismo de los emprendedores autónomos que no tienen capacidad de generar empleo. Por otro lado, es uno de los países con mayor descentralización política, administrativa y legislativa del mundo. Estos dos factores, que a priori pudieran parecer independientes, tienen una importante relación. En España, las Comunidades Autónomas tienen capacidad regulatoria en aspectos vitales que afectan a todas las etapas de desarrollo de una empresa, lo que lleva a la existencia de diferencias a nivel regional. El informe Doing Business para España (Banco Mundial, 2015) es claro en este sentido, pues entre sus principales conclusiones, destaca el hecho de que los emprendedores encuentran importantes diferencias regionales a la hora de hacer negocios. De hecho, La Rioja y la Comunidad de Madrid sobresalen en facilitar los negocios, frente a Aragón y Galicia, territorios en donde se concluye una mayor dificultad a la hora de hacer negocios. Por lo tanto, la perspectiva institucional no es un factor menor para tener en cuenta. De hecho, la evidencia señala la importancia del diseño y la eficiencia del sistema judicial a la hora de promover el espíritu emprendedor (Desai, Gompers y Lerner, 2005, Ardagna y Lusardi, 2008; Stephen, Urbano y van Hemmen, 2009; Chemin, 2009; Lichand y Soares, 2011; GarcíaPossada y Mora-Sanguinetti, 2014) o la especialización productiva (MoraSanguinetti y Spruk, 2018). Adicionalmente, y en términos de carga regulatoria, en España se observa una tendencia a publicar cada vez más normas, al contrario que en el resto de Europa (Consejo General de Economistas, 2016), lo que dificulta su asimilación por parte de los emprendedores. 
Por su parte, desde una perspectiva económica, las regiones españolas han experimentado, a lo largo de las últimas décadas, un proceso de convergencia en términos de renta per cápita, aunque con una intensidad que se puede considerar reducida (Puente, 2017), hecho que probablemente influya en el entorno económico regional de los emprendedores y en sus condiciones relativas con otras regiones.

El fracaso, como etapa final del proceso emprendedor, no es ajeno a la influencia de estos factores. Sin embargo, y a pesar de haber experimentado un importante un crecimiento a lo largo de los últimos años, la evidencia en torno a la influencia de los factores macroeconómico e institucionales sobre el fracaso empresarial todavía es relativamente escasa (Tascón y Castaño, 2012), siendo Altman (1968) uno de los autores pioneros en proponer el uso de factores macroeconómicos en el análisis del fracaso empresarial. Atendiendo a las variables analizadas, los autores que han estudiado el impacto de las variables macroeconómicas se han centrado, normalmente, en variables como el PIB o el output gap (Benito, Delgado y Pages, 2004; Halim, Ahmad, Daud y Marzuki, 2008; Hol, 2007; Carling, Jacobson, Lindé, Roszbach, 2007; Contreras, 2016), el nivel de paro (Buehler, Kaiser y Jaeger, 2012; Contreras, 2016; Acosta, Fernández y Ganga, 2019 ), la presión impositiva (Buehler et al., 2012) o, la disponibilidad del crédito (Altman, 1983; Liu 2004). Por otra parte, la importancia del sector de actividad en la propensión al fracaso también ha estado presente en la literatura (Chava y Jarrow, 2004; Salman, Friedrichs y Shukur, 2011; Contreras, 2016). Finalmente, los autores que han analizado el influjo de factores institucionales no son abundante, aunque destacan las aportaciones de Lee Peng y Barney (2007); Armour y Cumming (2008) o Lee, Yamakawa, Peng y Barney (2011), que consideran el marco legal, Davydenko y Franks, 2008, que centran sus esfuerzos en la influencia de las leyes de protección de los acreedores o Contreras, 2016, que analiza indicadores sobre los niveles de corrupción o grado de cumplimiento de contratos. Sin embargo, la mayoría de las aportaciones tratan el tema desde una perspectiva nacional o agregada, pero sin profundizar en factores de índole regional. En este sentido, y para el caso español, destaca el trabajo de Garrido, Gallo y Martínez (2016), que encuentran evidencia sobre el incremento de la ratio de procedimientos concursales y la actividad productiva regional.

En línea a la literatura previa analizada, el presente trabajo busca profundizar en los factores macroeconómicos e institucionales que influyen en el fracaso de la actividad emprendedora desde una óptica regional. Más concretamente, el objeto de estudio son los emprendedores autónomos, colectivo de vital importancia en la economía española y que no ha recibido la merecida atención por parte de la investigación en fracaso empresarial (con destacadas e interesantes 
excepciones como la aportación de Álvarez y Otero, 2006). Para ello, y tras analizar la vital importancia de los empresarios autónomos en la estructura empresarial española, se parte de los microdatos de la Encuesta de Población Activa (EPA) y se analizan las características socioeconómicas que influyen en el fracaso temprano de la actividad de los emprendedores autónomos a lo largo del periodo 2008-2017, profundizando, a su vez, en la hipótesis de existencia de diferencias regionales en torno al fracaso y que se pueden explicar, en parte, por los factores sectoriales, institucionales y macroeconómicos. Con el fin de confirmar dicha hipótesis, se desarrollan modelos de regresión logística multinivel en las que las variables macroeconómicas e institucionales se introducen en base a su naturaleza regional, es decir, a nivel Comunidad Autónoma.

Así pues, el trabajo se estructura de la siguiente manera: en primer lugar, se realiza un análisis que pone en contexto la importancia de los empresarios autónomos en la economía española, su dinámica y evolución, las principales fuentes de amenaza provenientes del entorno, y el comportamiento de la mortalidad empresarial de las empresas ya activas, y de las de nueva constitución, de forma que se justifica el interés mostrado en este colectivo y la existencia de diferencias regionales en la mortalidad empresarial, principalmente para el caso de los autónomos. En segundo lugar, se definen las hipótesis que el trabajo trata de contrastar. En tercer lugar, se especifica la muestra utilizada y los criterios seguidos en su construcción, así como la metodología aplicada. En cuarto lugar, se definen las variables incluidas en el estudio y, en su caso, los criterios de construcción de las mismas. En quinto lugar, se muestran los resultados obtenidos para, finalmente, señalar las principales conclusiones del trabajo.

\section{LA IMPORTANCIA DEL EMPRESARIO AUTÓNOMO EN LA ECONOMÍA ESPAÑOLA}

Un rápido vistazo a la estructura empresarial española permitiría llegar a una rápida y certera conclusión: España es un país de Pymes. Esta afirmación se sustenta por un dato incontestable: de las 3.337.646 empresas activas a 1 de enero de 2018, un 99,88\% eran Pymes (según el criterio de tamaño, es decir, entre 0 y 249 asalariados). En realidad, España no tiene una estructura empresarial, en términos de tamaño empresarial, muy alejada de la Unión Europea de los veintiocho. De hecho, las cifras mostradas en la tabla 1 permiten apreciar que el 99,8\% de las empresas de la UE-28 son Pymes, si bien es cierto que la diferencia estructural se encuentra en la composición de las Pymes, más que en su número absoluto. 
Tabla 1. Porcentaje de empresas según estrato de asalariados, en España y en la UE-28

\begin{tabular}{|c|c|c|c|c|c|c|}
\hline & $\begin{array}{c}\text { Microempresas } \\
\text { sin asalariados }\end{array}$ & $\begin{array}{c}\text { Microempresas } \\
\mathbf{1} \text { a 9 }\end{array}$ & $\begin{array}{c}\text { Pequeñas } \\
\mathbf{1 0} \text { a 49 }\end{array}$ & $\begin{array}{c}\text { Medianas } \\
\mathbf{5 0} \text { a 249 }\end{array}$ & $\begin{array}{c}\text { Pymes 0 } \\
\mathbf{a} \mathbf{2 4 9}\end{array}$ & $\begin{array}{c}\text { Grandes } \\
\mathbf{2 5 0} \text { y más }\end{array}$ \\
\hline España & $55,3 \%$ & $40,1 \%$ & $3,8 \%$ & $0,6 \%$ & $99,9 \%$ & $0,1 \%$ \\
\hline UE & \multicolumn{2}{|c|}{$93,1 \%$} & $5,8 \%$ & $0,9 \%$ & $99,8 \%$ & $0,2 \%$ \\
\hline
\end{tabular}

Fuente: Ministerio de Industria, Comercio y Turismo. Retrato de la Pyme (2019).

De esta forma, se observa que en España un 95,4\% de las empresas tienen menos de 9 asalariados (o incluso no tienen), frente al 93,1\% de la UE-28. De la misma forma, aunque se incremente el número de asalariados, en el caso de las pequeñas, medianas o de las grandes empresas, España presenta una menor proporción relativa con respecto a la UE-28. Esta estructura empresarial tan dependiente de los empresarios autónomos no se ha visto alternada a lo largo de los últimos veinte años, como se puede ver en el gráfico 1 .

En definitiva, en una economía cuya estructura empresarial se fundamenta en las pequeñas y medianas empresas, como es el caso de la española, la figura del empresario autónomo adquiere especial relevancia, siendo necesario profundizar en sus características más específicas que permitan, de esta forma, definir las políticas económicas más adecuadas para fomentar su sostenibilidad y adecuado crecimiento. Pero ¿A qué denominar autónomo? Las respuestas pueden ser múltiples en función del enfoque o los datos a tratar. En este trabajo se sigue la definición de empresario autónomo que recoge el Ministerio de Industria, Comercio y Turismo ${ }^{1}$ y que se basa, a su vez, en los datos Ministerio de Trabajo, Migraciones y Seguridad Social ${ }^{2}$, de forma que "se consideran como empresas sin asalariados los autónomos propiamente dicho sin asalariados. Los autónomos propiamente dichos son aquellos trabajadores afiliados a alguno de los regímenes por cuenta propia de la Seguridad Social que no están integrados en sociedades mercantiles, cooperativas ni en otras entidades societarias. Tampoco se consideran autónomos propiamente dicho los que figuran como colaboradores familiares y los que están registrados formando parte de algún colectivo especial de trabajadores". Adicionalmente, en este trabajo se considerará empresario y emprendedor como sinónimos.

\footnotetext{
${ }^{1}$ Informe mensual "Cifras Pyme".

${ }^{2}$ Informe trimestral "Trabajadores autónomos, personas físicas, en alta en la Seguridad Social"
} 
Gráfico 1: Porcentaje de empresas según estrato de asalariados en España (1999-2018)

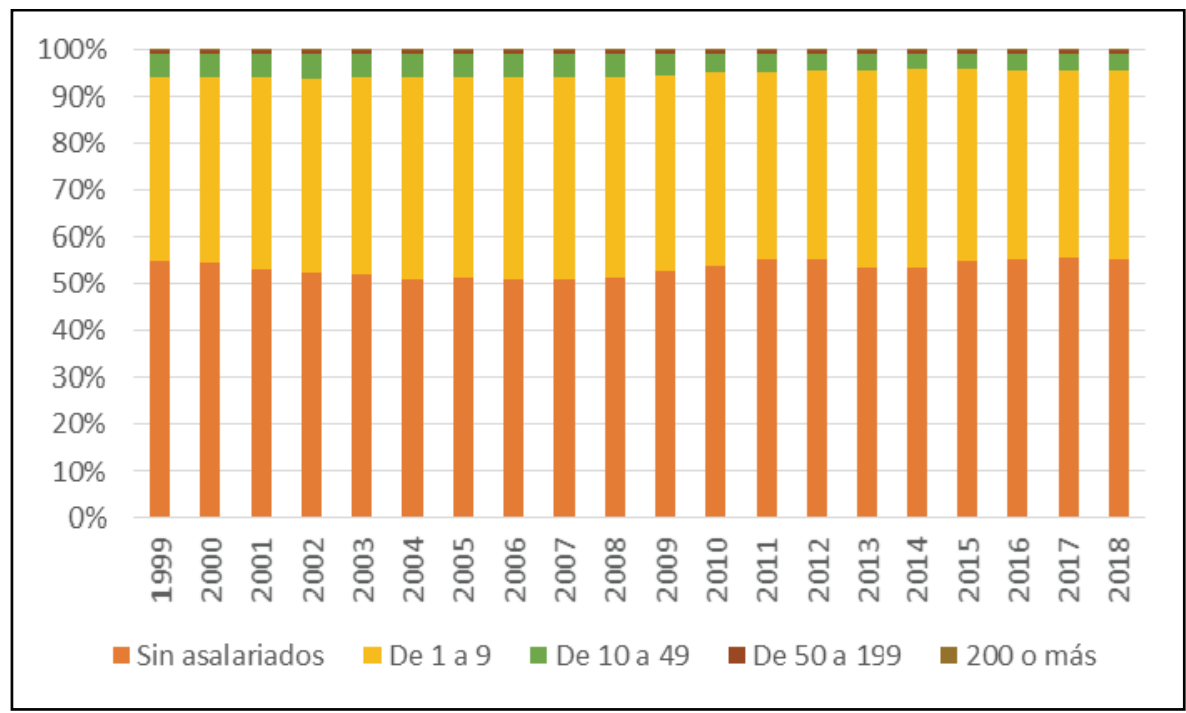

Fuente: Elaboración propia: Datos del DIRCE (INE)

Por lo tanto, se considera los autónomos como empresas sin asalariados. Así pues, los datos del Ministerio de Trabajo, Migraciones y Seguridad Social indican que, a 31 de diciembre de 2018, había registrados un total de 1.993 .902 autónomos en España, distribuidos según se pone de manifiesto en la tabla 2, destacando que los 434.104 empresarios autónomos con asalariados dan empleo a 887.093 personas, lo que supone un 4,5\% del total de ocupados a cierre de 2018 .

Destaca el hecho de que, dentro del número de autónomos sin asalariados, se incluyan 9.467 autónomos económicamente dependientes $(0,61 \%$ del total de autónomos sin asalariados). Este colectivo no se dedica a una actividad empresarial, sino a trabajadores autónomos que tienen una fuerte relación de dependencia con una empresa, para la cual trabajan (casi) en exclusiva y de la cual dependen más del $75 \%$ de sus ingresos, a la vez que apenas tienen control sobre aspectos clave de su trabajo (Malo, 2018). 
Tabla 2. Distribución de la situación profesional de los autónomos en España

\begin{tabular}{|c|r|}
\hline Autónomos Personas Físicas & 1.993 .902 \\
\hline Número de Autónomos sin asalariados & 1.559 .798 \\
\hline$\bullet \quad$ Autónomos económicamente dependientes & 9.467 \\
\hline Número de Autónomos con asalariados & 434.104 \\
\hline$\bullet \quad$ Número de Autónomos con 1 trabajador & 225.842 \\
\hline • Número de Autónomos con 2 trabajadores & 92.010 \\
\hline$\bullet \quad$ Número de Autónomos con 3 trabajadores & 45.798 \\
\hline • Número de Autónomos con 4 trabajadores & 25.202 \\
\hline • Número de Autónomos con 5 o más \\
trabajadores
\end{tabular}

Fuente: Ministerio de Trabajo, Migraciones y Seguridad Social

Más allá de trabajar con datos relativos al tamaño medido por número de empleados, resulta especialmente interesante, con el objetivo de indagar en esta realidad de la que hasta ahora sólo se ha navegado por la superficie, atender a la forma jurídica de estructurar las empresas y su evolución a lo largo de los últimos años. En este sentido, en España, de un total de 3.373.646 empresas activas a 1 de enero de 2018, un 53,5\% eran personas físicas, si bien es cierto que su peso se había reducido desde el 65,4\% observado en 1999 (Gráfico 2).

Gráfico 2: Porcentaje de empresas según forma jurídica en España (1999-2018)

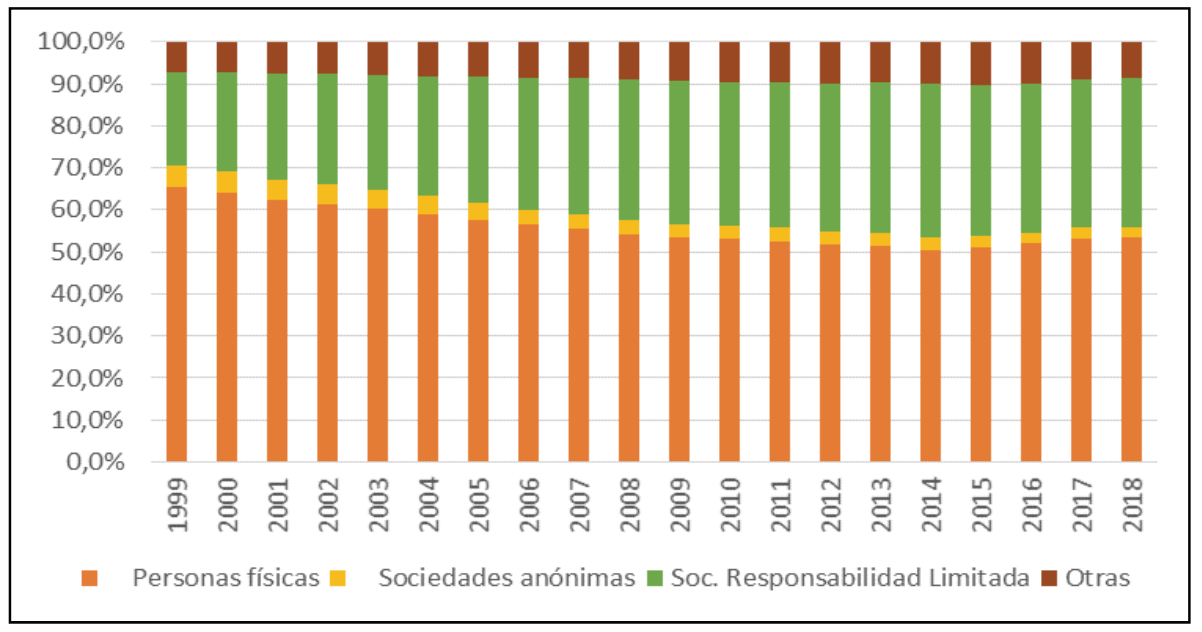

Fuente: Elaboración propia: Datos del DIRCE (INE) 
En el gráfico 2 se puede apreciar, no sólo la reducción del peso de las personas físicas a lo largo de los últimos años, sino su sustitución por la figura del empresario de responsabilidad limitada, que se ha incrementado desde un $22,2 \%$ en 1999 hasta un $35,4 \%$ en 2018. También es destacable la pérdida de importancia de la Sociedad Anónima como forma jurídica, habiéndose reducido desde el 5,3\% en 1999 hasta 2,4\% en 2018.

A su vez, y atendiendo al importante colectivo de las empresas que no tienen contratadas a ningún trabajador al que se ha hecho mención anteriormente (un $55,3 \%$ del total), un $66,3 \%$ eran personas físicas a inicios del 2018 , aunque eso supone veinte puntos porcentuales menos respecto a 1999 (Gráfico 3), aumentando la importancia, al igual que ocurre en total de empresas, de la figura de la sociedad de responsabilidad limitada como alternativa a la figura del empresario individual. No obstante, aunque este comportamiento parece seguir un componente tendencia, sí es cierto que en los últimos cuatro años la importancia relativa del empresario autónomo se ha incrementado ligeramente (tres puntos porcentuales).

Gráfico 3: Porcentaje de empresas sin asalariados según forma jurídica en España (1999-2018)

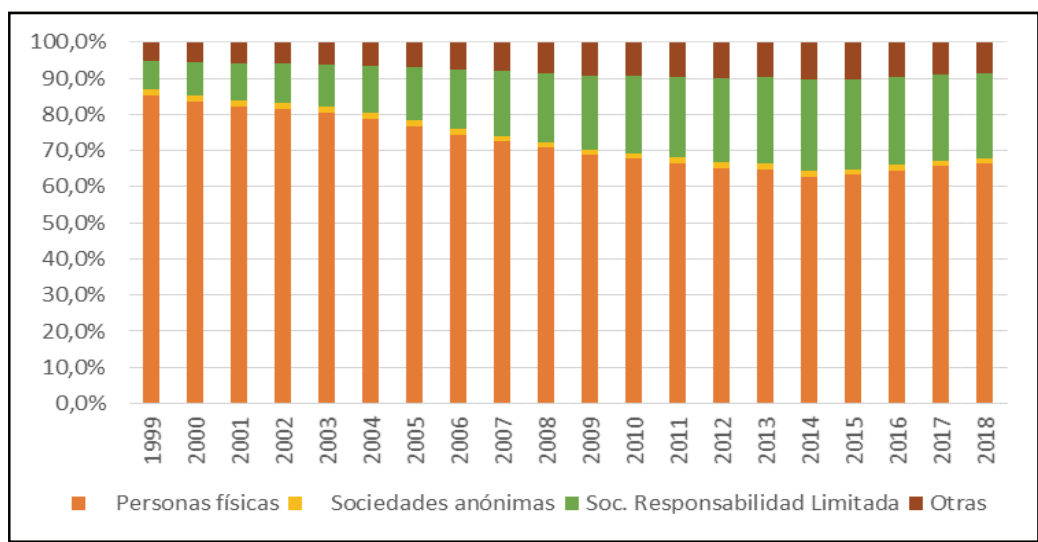

Fuente: Elaboración propia: Datos del DIRCE (INE)

Queda clara, a la vista de los datos mostrados, la importancia de los empresarios autónomos (personas físicas) a lo largo de los últimos años en España. Sin embargo y más allá de las "grandes cifras", ¿Qué perfil tienen los empresarios autónomos españoles? Es indudable que responder a esta pregunta con solvencia permitirá comprender mejor sus necesidades, así como las oportunidades y amenazas a las que hacen frente y que, como no hay que dejar de reiterar, condicionan en desarrollo de la economía española. 
Para responder esta pregunta, los datos del Ministerio de Trabajo, Migraciones y Seguridad Social, junto con los de la Encuesta de Población Activa (en adelante EPA) son especialmente útiles, pues permiten trazar un perfil socioeconómico de los empresarios autónomos españoles.

En primer lugar, existen importantes diferencias por sexo entre las mujeres y los hombres que deciden emprender un proyecto empresarial como autónomos, si bien es cierto que se observa una tendencia a la convergencia en el tiempo que muestra que cada vez más mujeres deciden poner en marcha un proyecto empresarial, principalmente cuando éste genera empleo (tabla 3 ).

Tabla 3. Diferencias por género en la estructura de los autónomos españoles.

\begin{tabular}{|l|c|c|c|c|}
\hline & \multicolumn{2}{|c|}{$\begin{array}{c}\text { Empresarios que } \\
\text { generan empleo }\end{array}$} & \multicolumn{2}{c|}{$\begin{array}{c}\text { Empresario sin asalariados o } \\
\text { trabajador independiente }\end{array}$} \\
\hline & Hombres & Mujeres & Hombres & Mujeres \\
\hline $\mathbf{2 0 0 6}$ & $75,3 \%$ & $24,7 \%$ & $68,8 \%$ & $31,2 \%$ \\
\hline $\mathbf{2 0 0 7}$ & $75,4 \%$ & $24,6 \%$ & $67,9 \%$ & $32,1 \%$ \\
\hline $\mathbf{2 0 0 8}$ & $74,7 \%$ & $25,3 \%$ & $67,5 \%$ & $32,5 \%$ \\
\hline $\mathbf{2 0 0 9}$ & $71,9 \%$ & $28,1 \%$ & $66,6 \%$ & $33,4 \%$ \\
\hline $\mathbf{2 0 1 0}$ & $71,9 \%$ & $28,1 \%$ & $66,8 \%$ & $33,2 \%$ \\
\hline $\mathbf{2 0 1 1}$ & $71,5 \%$ & $28,5 \%$ & $66,1 \%$ & $33,9 \%$ \\
\hline $\mathbf{2 0 1 2}$ & $70,3 \%$ & $29,7 \%$ & $66,3 \%$ & $33,7 \%$ \\
\hline $\mathbf{2 0 1 3}$ & $69,9 \%$ & $30,1 \%$ & $66,4 \%$ & $33,6 \%$ \\
\hline $\mathbf{2 0 1 4}$ & $68,8 \%$ & $31,2 \%$ & $66,7 \%$ & $33,3 \%$ \\
\hline $\mathbf{2 0 1 5}$ & $69,9 \%$ & $30,1 \%$ & $66,0 \%$ & $34,0 \%$ \\
\hline $\mathbf{2 0 1 6}$ & $68,9 \%$ & $31,1 \%$ & $65,4 \%$ & $34,6 \%$ \\
\hline $\mathbf{2 0 1 7}$ & $69,9 \%$ & $30,1 \%$ & $65,7 \%$ & $34,3 \%$ \\
\hline $\mathbf{2 0 1 8}$ & $68,7 \%$ & $31,3 \%$ & $65,8 \%$ & $34,2 \%$ \\
\hline
\end{tabular}

Fuente: Elaboración propia. Datos de la EPA

En relación con los sectores de actividad en donde los empresarios autónomos enfocan sus proyectos, no cabe duda de la gran importancia de los servicios, reflejo, por otra parte, de una estructura económica española basada principalmente en la prestación de servicios. De esta forma, tal y como refleja el gráfico 4, el peso de este sector supera el $70 \%$ tanto para el caso de empresarios con asalariados como para el caso de empresarios sin asalariados o trabajadores independientes. No obstante, y ante un peso similar en el sector de la construcción, la diferencia se aprecia en los sectores agrícola e industrial, de forma que los empresarios que generan empleo tienen más peso en la industria que en la agricultura, invirtiéndose dicha situación para el caso de empresarios sin asalariados o trabajadores independientes. 
Gráfico 4: Empresarios autónomos y sectores de actividad

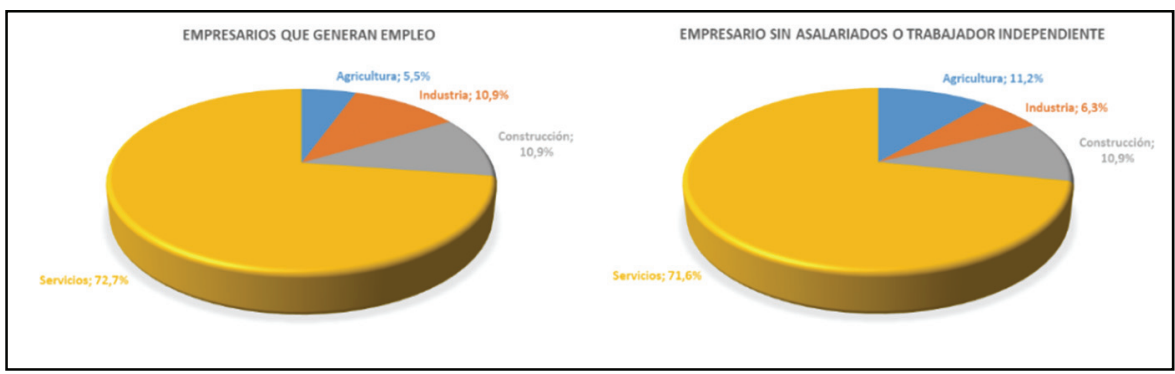

Fuente: Elaboración propia: Datos de la EPA

En lo que respecta a la distribución por edad, el gráfico 5 permite apreciar que el mayor porcentaje de autónomos (tanto en el caso de no tener asalariados como en el caso de tenerlos) a cierre de 2018 se sitúa en el rango de edad de 40 a 59 años, con más del $60 \%$. Ello se debe, en parte, a una herencia de la crisis económica manifestada en forma de situación profesional más precaria en estos intervalos de edad, en los que muchas personas se han visto privadas de su empleo a través de EREs, prejubilaciones o quiebras de empresas y se han visto obligados a transformar sus trayectorias laborales, motivando en numerosas ocasiones la creación de proyectos empresariales autónomos, ya sea por oportunidad de mercado (con facilidad de financiación gracias a las indemnizaciones por despido obtenidas) o por necesidad.

Gráfico 5: Empresarios autónomos y tramos de edad

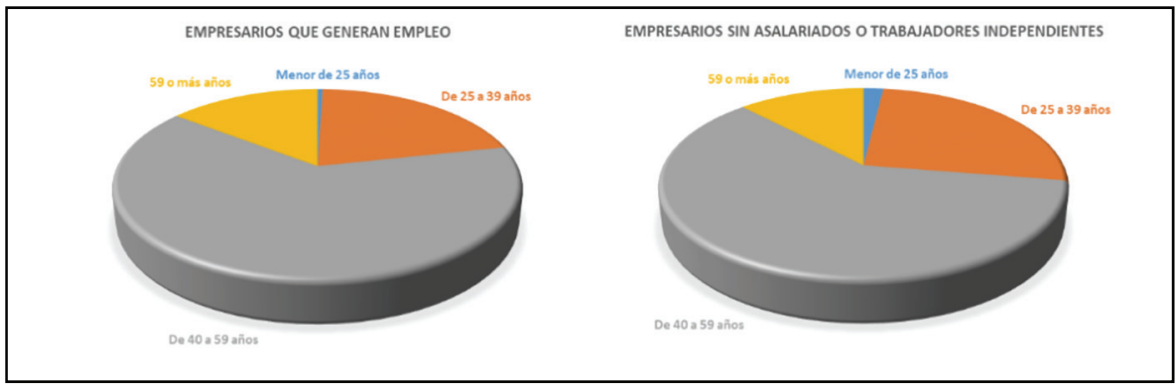

Fuente: Elaboración propia: Datos de la EPA

Adicionalmente, y en relación la importancia de los tramos mayores de edad, no deja de ser interesante señalar que el $86 \%$ de los autónomos cotizan a la Seguridad Social por la base mínima, lo que les concede mínima cobertura a la hora de recibir las prestaciones correspondientes de la Seguridad Social, como 
es el caso de las pensiones por jubilación, lo cual resulta preocupante si se suma la edad cercana a la jubilación de la mayoría de autónomos y el contexto de una sociedad caracterizada por la mayor longevidad, en la que la escasez de recursos en la etapa pasiva de la vida de las personas es un problema económico y social.

Por último, una vez vistas las principales características socioeconómicas de los autónomos españoles, conviene dar un paso más y profundizar en los motivos que han llevado a los autónomos españoles a poner en marcha un proyecto y a tomar las decisiones que caracterizan, en parte, a este colectivo. Para ello, es especialmente relevante el módulo especial de la EPA de 2017, dedicado a la actividad por cuenta propia, pues proporciona información sobre las diversas motivaciones de los empresarios autónomos.

En este sentido, dado que el objetivo final del trabajo es conocer el perfil de los autónomos y las razones que llevan, en última instancia, al abandono de la actividad, la primera pregunta que viene a la mente es con qué dificultades se encuentran los empresarios autónomos a la hora de llevar a cabo sus proyectos. Así pues, los resultados de la tabla 4 son esclarecedores, destacando que una importante mayoría, tanto de hombres como de mujeres y tanto autónomos con empleados como sin ellos, declaran no haber sufrido dificultades a la hora de trabajar por cuenta propia. Para los hombres, independientemente de si generan empleo o no, la mayor dificultad proviene del retraso en los pagos o, directamente, el impago de los clientes, mientras que para las mujeres el mayor inconveniente proviene de los períodos sin clientes, sin tener ningún pedido o proyecto en el que trabajar. No parece un inconveniente de los más importantes, por el contrario, la escasez de financiación para ninguno de los colectivos estudiados o los periodos de precariedad financiera, salvo para un porcentaje que ronda el 6 y $8 \%$ de la muestra analizada. Igualmente, no parece un inconveniente importante el nivel inadecuado de carga administrativa.

En relación con las dificultades señaladas, a la hora de evaluar los retos y oportunidades que concede el entorno empresarial, no es posible distinguir entre microempresas y autónomos, dada la estructura de información proporcionada por el INE en su módulo de entorno empresarial, dentro de los indicadores de confianza empresarial. Sin embargo, se considera fundamental para este trabajo conocer estos aspectos y profundizar en ellos, dada la metodología de investigación seguida. A estos efectos, según los propios empresarios con menos de diez trabajadores, los factores más importantes que originan el dinamismo procedente del entorno empresarial en 2018 se encuentran en la demanda de sus productos (con un $86 \%$ que lo consideran de importancia media o alta), la fiscalidad (con un $85 \%$ que lo consideran de importancia media o alta), la 
regulación (sólo un 17\% lo considera de importancia baja), en el entorno económico (con un $80 \%$ que opinan que tiene importancia media o alta), la eficiencia del mercado de trabajo (con un 79\% que lo consideran de importancia media o alta) o la morosidad (con un $73 \%$ que lo señalan con importancia media o alta).

Tabla 4. Dificultades de trabajar por cuenta propia

\begin{tabular}{|l|c|c|c|c|}
\hline & \multicolumn{2}{|c|}{$\begin{array}{c}\text { Autónomos que } \\
\text { generan empleo }\end{array}$} & \multicolumn{2}{c|}{$\begin{array}{c}\text { Autónomos sin } \\
\text { asalariados }\end{array}$} \\
\hline & Hombres & Mujeres & Hombres & Mujeres \\
\hline $\begin{array}{l}\text { No tener control en la fijación del precio } \\
\text { de su propio trabajo }\end{array}$ & $3 \%$ & $3 \%$ & $4,7 \%$ & $4 \%$ \\
\hline Falta de financiación para su negocio & $6 \%$ & $7 \%$ & $6,0 \%$ & $6 \%$ \\
\hline Retraso o falta de pago de los clientes & $18 \%$ & $7 \%$ & $11,6 \%$ & $7 \%$ \\
\hline Un nivel inadecuado de carga administrativa & $5 \%$ & $4 \%$ & $2,8 \%$ & $2 \%$ \\
\hline Falta de ingresos en caso de enfermedad & $4 \%$ & $9 \%$ & $7,9 \%$ & $8 \%$ \\
\hline Períodos de precariedad financiera & $7 \%$ & $7 \%$ & $8,1 \%$ & $8 \%$ \\
\hline $\begin{array}{l}\text { Períodos sin clientes, sin tener ningún } \\
\text { pedido o proyecto en el que trabajar }\end{array}$ & $8 \%$ & $10 \%$ & $15,7 \%$ & $16 \%$ \\
\hline $\begin{array}{l}\text { Otras dificultades no mencionadas } \\
\text { anteriormente }\end{array}$ & $15 \%$ & $18 \%$ & $13,0 \%$ & $15 \%$ \\
\hline No ha sufrido ninguna dificultad & $29 \%$ & $32 \%$ & $25,4 \%$ & $29 \%$ \\
\hline No sabe/No contesta & $5 \%$ & $3 \%$ & $4,7 \%$ & $4 \%$ \\
\hline
\end{tabular}

Fuente: Elaboración propia: Datos de la EPA (Módulo especial 2017)

Las anteriores opiniones están estrechamente relacionadas a las causas de trabajar por cuenta ajena. Así pues, el $29 \%$ de los hombres y el $28 \%$ de las mujeres declaran que trabajan por cuenta ajena al presentarse una buena oportunidad. Este porcentaje se reduce al $18 \%$ y $21 \%$ respectivamente si la opinión proviene de autónomos sin asalariados. Adicionalmente, también resulta muy relevante que el $25 \%$ de las mujeres y el $27 \%$ de los hombres que ostentan un negocio con asalariados continuaron con un negocio familiar, frente a porcentajes también altos en el caso de autónomos sin asalariados ( $23 \%$ de hombres y $19 \%$ de mujeres).

Asimismo, es una buena noticia saber que el $88 \%$ de los hombres y el $89 \%$ de las mujeres que ejercen por cuenta propia se encuentran satisfechas hasta cierto punto o en gran medida con su trabajo.

En tercer lugar, las razones de no contratar empleados o las expectativas para generar empleo resultan de especial interés en un contexto como el 
español, con un mercado laboral caracterizado por los (todavía) altos niveles de desempleo. Así las cosas, la gran mayoría de los empresarios autónomos ( $57 \%$ de los hombres y $61 \%$ de las mujeres) señalan que no hay suficiente trabajo a la hora de justificar que no tienen empleados, destacando, a su vez que el $14 \%$ de las mujeres y el $16 \%$ de los hombres prefieren trabajar solos y que el $8 \%$ de los hombres y el $8 \%$ de las mujeres consideran las cotizaciones sociales demasiado elevadas.

Por otra parte, ante la expectativa de contratar trabajadores o subcontratar servicios a lo largo de los siguientes doce meses, la gran mayoría de los empresarios son tajantes: el $59 \%$ de los hombres y el $70 \%$ de las mujeres que ya cuentan con trabajadores en sus plantillas declaran que no tienen intención de generar más empleo. No obstante, en el caso de los autónomos que no tienen asalariados, este porcentaje alcanza el $85 \%$ en el caso de las mujeres y el $82 \%$ respecto a los hombres.

En el caso de prever contratar, sólo el 4\% de los autónomos que ya generan empleo prevén contratar bajo un contrato indefinido, frente al $12 \%$ que prevén hacerlo bajo figuras contractuales temporales. Estos porcentajes se reducen hasta el $1 \%$ y $4 \%$ respectivamente cuando se preguntan a los empresarios autónomos que no tienen asalariados a su cargo.

\section{EL FRACASO DEL EMPRESARIO AUTÓNOMO EN ESPAÑA}

No cabe duda, a la luz de los datos mostrados en el apartado anterior, de la vital importancia de los empresarios autónomos en la economía española y en la generación de empleo, asignatura pendiente del sistema económico. Se han repasado, a su vez, las principales dificultades y factores del entorno a los que se encuentran expuestos en el día a día de su gestión. Todo ello permite disponer de un tejido empresarial autónomo en el que el $72 \%$ de los empresarios que generan empleo llevan más de seis años desarrollando su proyecto, ascendiendo al $60 \%$ el porcentaje de los autónomos sin asalariados. Por lo tanto, igual de importante es fomentar el espíritu emprendedor y generar nuevas ideas como consolidar el tejido empresarial ya desarrollado por los autónomos, generando un contexto que facilite el día a día de los empresarios.

Es por ello que resulta imprescindible, como parte del conocimiento de la realidad empresarial autónoma, analizar su aspecto menos atractivo: el abandono o fracaso de la actividad. 
Atendiendo a los datos de la EPA, los desempleados que trabajaban como autónomos en lo últimos doce meses ascienden a un $0,2 \%$ en el caso de autónomos que generaban empleo y $1,7 \%$ en el caso de autónomos sin asalariados. Quizás no parezcan cifras relativamente altas, pero no se debe olvidar que cuando un autónomo abandona su actividad, puede acarrear el despido de otros trabajadores, así como problemas para otras empresas en forma de impagos.

En términos de número de empresas, tal y como muestra el gráfico 6, aproximadamente el $70 \%$ de las empresas que causan baja cada año no tienen asalariados. Además, de las empresas que jurídicamente tienen forma de persona física, el número empresas sin asalariados que se dan de baja asciende hasta el 76,5\%, reflejando la situación de debilidad de las empresas sin asalariados. Ambas magnitudes han experimentado un ligero repunte desde 2007.

Gráfico 6: Tasa de mortalidad entre las empresas sin asalariados

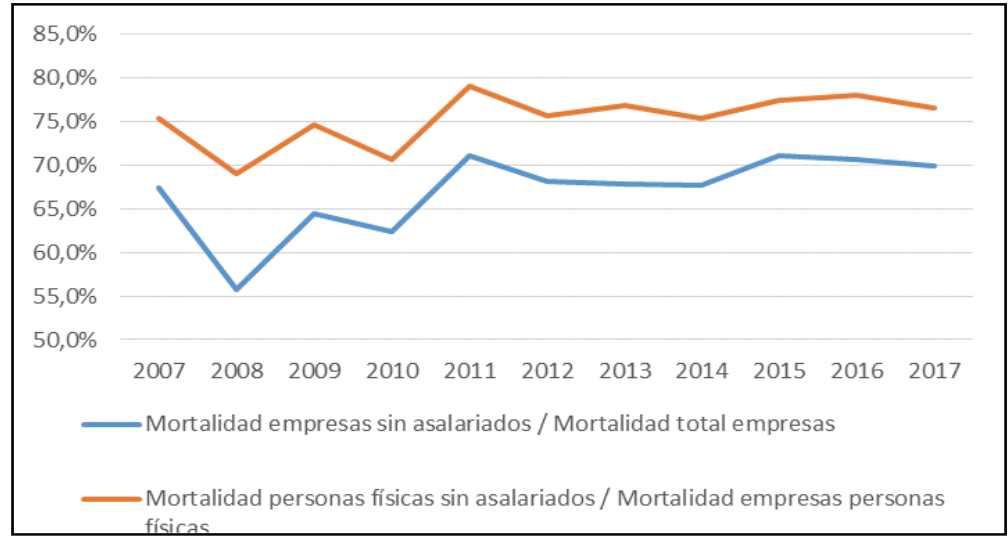

Fuente: Elaboración propia: Datos del DIRCE (INE)

Las tasas de mortalidad anteriores se reflejan sobre el total de empresas activas que causan baja. Sin embargo, otra perspectiva sumamente interesante supone atender al número de nuevas empresas que causan baja tras iniciar su actividad. La tabla 5 representa, en este sentido, las tasas de mortalidad o fracaso empresarial de las empresas sin asalariados o microempresas, que se crean en un momento $t$ y cesan la actividad en el año $t+1$, en el año $t+2$, en el año $t+3$, en el año $t+4$ ó en el año $t+5$. De esta forma, se puede analizar la evolución de la mortalidad empresarial por "añadas", de forma que se puede apreciar un peor comportamiento de fracaso a lo largo de los años o, dicho de otra manera, las empresas que se crean en los años más recientes demuestran ser más débiles y fracasar antes que las constituidas en 2007. 
Tabla 5. Tasas de fracaso empresarial en España por tamaño y añada

\begin{tabular}{|c|c|c|c|c|c|c|c|c|c|c|}
\hline Tamaño & $\begin{array}{l}\text { Año de } \\
\text { fracaso }\end{array}$ & 2008 & 2009 & 2010 & 2011 & 2012 & 2013 & 2014 & 2015 & 2016 \\
\hline \multirow{5}{*}{$\begin{array}{c}\text { Sin } \\
\text { asalariados }\end{array}$} & $1^{\mathrm{o}}$ año & $20,2 \%$ & $22,5 \%$ & $21,0 \%$ & $25,6 \%$ & $26,4 \%$ & $26,1 \%$ & $24,6 \%$ & $25,7 \%$ & $24,7 \%$ \\
\hline & $2^{\circ}$ año & $34,1 \%$ & $35,6 \%$ & $35,8 \%$ & $36,6 \%$ & $40,0 \%$ & $40,7 \%$ & $39,0 \%$ & $37,4 \%$ & $40,5 \%$ \\
\hline & $3^{\circ}$ año & $40,0 \%$ & $45,5 \%$ & $46,1 \%$ & $47,0 \%$ & $48,5 \%$ & $50,5 \%$ & $50,2 \%$ & $47,7 \%$ & $47,3 \%$ \\
\hline & $4^{\circ}$ año & $45,8 \%$ & $48,9 \%$ & $53,4 \%$ & $54,2 \%$ & $55,3 \%$ & $55,9 \%$ & $57,6 \%$ & $56,5 \%$ & $54,9 \%$ \\
\hline & $5^{\circ}$ año & - & $53,3 \%$ & $55,4 \%$ & $59,6 \%$ & $60,7 \%$ & $60,9 \%$ & $61,4 \%$ & $62,4 \%$ & $62,0 \%$ \\
\hline \multirow{5}{*}{$\begin{array}{c}1 \text { a } 4 \\
\text { asalariados }\end{array}$} & $1^{\circ}$ año & $25,6 \%$ & $16,7 \%$ & $18,4 \%$ & $16,9 \%$ & $17,4 \%$ & $17,4 \%$ & $16,5 \%$ & $15,6 \%$ & $15,5 \%$ \\
\hline & $2^{o}$ año & $30,0 \%$ & $37,5 \%$ & $30,2 \%$ & $30,1 \%$ & $30,1 \%$ & $30,3 \%$ & $29,1 \%$ & $27,3 \%$ & $27,7 \%$ \\
\hline & $3^{\circ}$ año & $34,9 \%$ & $40,9 \%$ & $46,7 \%$ & $39,3 \%$ & $40,3 \%$ & $40,2 \%$ & $39,2 \%$ & $37,2 \%$ & $36,8 \%$ \\
\hline & $4^{\circ}$ año & $37,8 \%$ & $44,1 \%$ & $49,0 \%$ & $52,9 \%$ & $47,2 \%$ & $47,6 \%$ & $47,6 \%$ & $45,6 \%$ & $45,1 \%$ \\
\hline & $5^{\circ}$ año & - & $45,6 \%$ & $51,2 \%$ & $55,0 \%$ & $58,6 \%$ & $53,1 \%$ & $53,6 \%$ & $53,0 \%$ & $52,2 \%$ \\
\hline \multirow{5}{*}{$\begin{array}{c}5 \text { a } 9 \\
\text { asalariados }\end{array}$} & $1^{\circ}$ año & $11,7 \%$ & $8,3 \%$ & $7,0 \%$ & $9,6 \%$ & $10,4 \%$ & $10,1 \%$ & $9,2 \%$ & $9,2 \%$ & $8,8 \%$ \\
\hline & $2^{\circ}$ año & $21,8 \%$ & $23,8 \%$ & $18,1 \%$ & $17,2 \%$ & $21,1 \%$ & $20,4 \%$ & $19,3 \%$ & $17,9 \%$ & $19,0 \%$ \\
\hline & $3^{\circ}$ año & $26,3 \%$ & $32,4 \%$ & $32,1 \%$ & $26,8 \%$ & $26,8 \%$ & $29,9 \%$ & $29,3 \%$ & $26,9 \%$ & $26,1 \%$ \\
\hline & $4^{\circ}$ año & $28,8 \%$ & $35,6 \%$ & $40,0 \%$ & $39,4 \%$ & $35,3 \%$ & $35,0 \%$ & $37,4 \%$ & $36,2 \%$ & $34,5 \%$ \\
\hline & $5^{\circ}$ año & - & $36,8 \%$ & $42,7 \%$ & $46,6 \%$ & $46,7 \%$ & $41,6 \%$ & $42,5 \%$ & $42,8 \%$ & $42,8 \%$ \\
\hline
\end{tabular}

Fuente: Elaboración propia con datos de EURSTAT

Así pues, de los datos señalados se pueden extraer varias conclusiones: en primer lugar, que la tasa de mortalidad temprana (a un año) se ha reducido a lo largo del tiempo en todos los colectivos excepto en el caso de empresas sin asalariados, en donde se ha visto incrementada en más de cuatro puntos porcentuales. En segundo lugar, destaca el hecho de que a los tres años de vida, en 2016 habían desaparecido prácticamente la mitad de las empresas creadas en 2013 , frente a tasas del $36 \%$ y $26 \%$ en el caso de empresas con hasta cuatro trabajadores y empresas con hasta nueve trabajadores, respectivamente, habiéndose incrementado en todos los segmentos a lo largo de los años, salvo en el caso de las empresas con más trabajadores, para las cuales la tasa de mortalidad a medio plazo se mantiene en 2016 en niveles de 2008. En tercer y último lugar, la tasa de mortalidad a los cinco años de vida se ha incrementado para el caso de todos los colectivos analizados, suponiendo, en resumen, que, para empresas de menos de cinco trabajadores, más de la mitad ha desaparecido en el transcurso de los cinco primeros años de vida, lo que debe dar pie a una profunda reflexión sobre las causas de este hecho y las medidas que podrían cambiar esta característica estructural de la economía española. 
En definitiva, es indudable que las altas tasas de mortalidad empresarial suponen una dificultad para la consolidación de un fuerte tejido empresarial en España, con las consecuencias que ello tiene sobre la productividad y la cantidad (y calidad) del empleo.

Dado el nivel de descentralización que existe en España, cabe la pregunta de si este hecho es homogéneo para todas las regiones o si bien, existen diferencias suficientes como para ser objeto de análisis. El gráfico 7 muestra, para cada Comunidad Autónoma, la tasa de fracaso a tres años (único dato disponible para este nivel de desagregación).

Gráfico 6: Tasa de mortalidad a 3 años entre las empresas con menos de 10 salariados $^{3}$

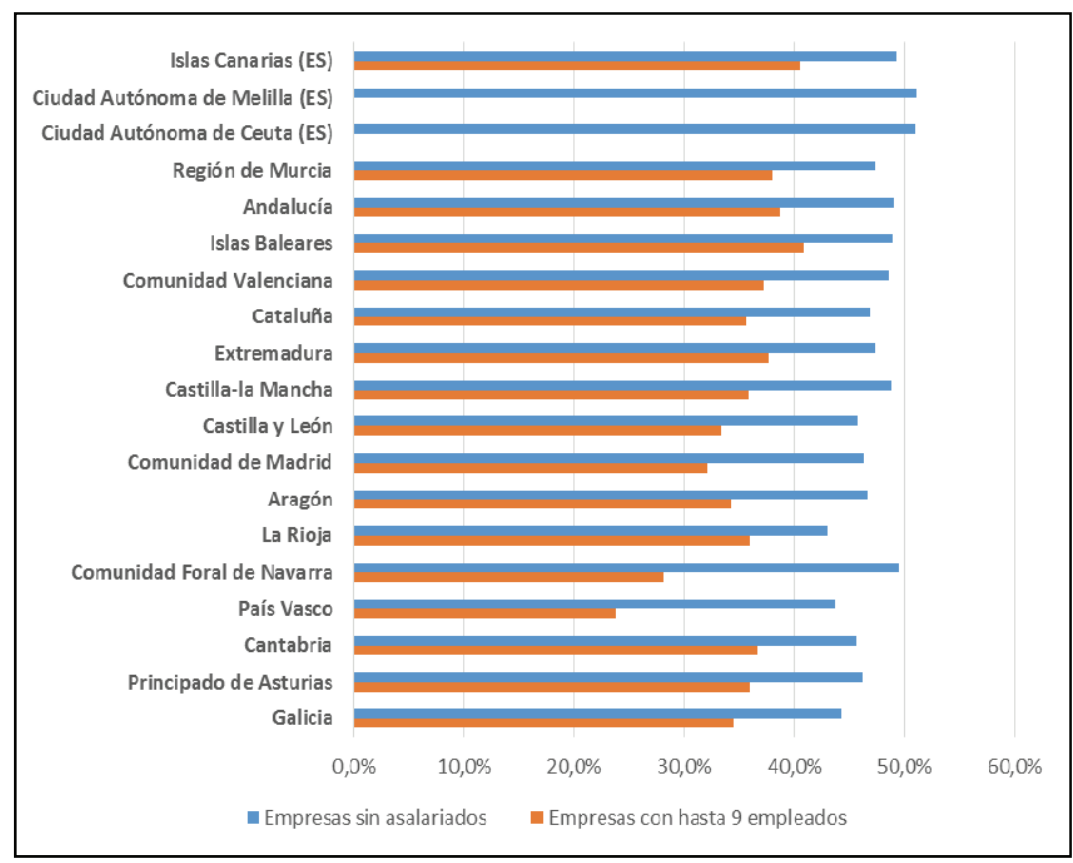

Fuente: Elaboración propia con datos de EURSTAT

Así las cosas, no cabe duda de la mayor tasa de fracaso a medio plazo entre los empresarios autónomos, especialmente en Comunidades Autónomas como Navarra y Castilla la Mancha, Andalucía, Baleares y Canarias, así como en las dos ciudades autónomas. En el caso de empresas con entre 1 y 9 asalariados, destacan especialmente las Islas Baleares y Canarias.

\footnotetext{
${ }^{3}$ No hay disponibles datos para Ceuta y Melilla en el caso de las microempresas.
} 
Por lo tanto, se aprecian ciertas diferencias en el fracaso empresarial por región y por tamaño, legitimando, por lo tanto, el análisis más profundo que se lleva a cabo en los siguientes apartados de este trabajo y destinado al segmento más propenso a fracasar: el de los empresarios autónomos.

\section{HIPÓTESIS DE TRABAJO}

Las hipótesis establecidas en el trabajo son de diversa índole, por lo que se pueden dividir según sean de índole general o según se basen en factores socioeconómicos, macroeconómicos o institucionales, tal y como se especifica a continuación:

H1: Existen diferencias regionales en la propensión al fracaso de los emprendedores autónomos.

H2: Existen diferencias debidas a la especialización sectorial de las regiones que influyen en la propensión al fracaso de los emprendedores autónomos.

\subsection{Características socioeconómicas}

H3: Los empresarios autónomos que crean empleo tienen menor propensión a fracasar, puesto que su actividad está más consolidada.

H4: Las diferencias por sexo influyen en la probabilidad a fracasar.

H5: Los emprendedores autónomos que tienen hijos tienen una menor propensión a fracasar.

H6: Tener un cónyuge que trabaja permite reducir la probabilidad de fracasar, pues disponen de un apoyo en la actividad y otras garantías financieras a la hora de obtener financiación (avales).

H7: Los emprendedores autónomos tienen mayor probabilidad a fracasar conforme más jóvenes son, dada su falta de experiencia.

H8: Es mayor la probabilidad a fracasar entre los emprendedores autónomos divorciados, separados o solteros que entre los casados.

H9: Los emprendedores autónomos con mayor nivel de formación y, por lo tanto, mayor edad de finalización de estudios, tienen menor probabilidad de fracaso, puesto que están mejor preparados para afrontar los retos de un negocio. 
4.2. Condicionantes macroeconómicos

H10: Mayor crecimiento económico de la Comunidad Autónoma reduce la propensión a fracasar de los emprendedores autónomos que ejercen su actividad en dicha comunidad.

H11: Mayor tasa de desempleo de la Comunidad Autónoma aumenta la propensión a fracasar de los emprendedores autónomos que ejercen su actividad en dicha comunidad.

H12: Mayor deuda pública de la Comunidad Autónoma aumenta la propensión a fracasar de los emprendedores autónomos que ejercen su actividad en dicha comunidad.

H13: El crecimiento del crédito en la Comunidad Autónoma reduce la propensión a fracasar de los emprendedores autónomos que ejercen su actividad en dicha comunidad.

H14: El crecimiento de la presión fiscal en la Comunidad Autónoma aumenta la propensión a fracasar de los emprendedores autónomos que ejercen su actividad en dicha comunidad.

\subsection{Condicionantes institucionales}

H15: Una mayor carga regulatoria de la Comunidad Autónoma con respecto al total de las regiones aumenta la propensión a fracasar de los emprendedores autónomos que ejercen su actividad en dicha comunidad.

H16: Una mayor transparencia de la Comunidad Autónoma reduce la propensión a fracasar de los emprendedores autónomos que ejercen su actividad en dicha comunidad.

H17: Una mayor ineficiencia del sistema judicial en la Comunidad Autónoma aumenta la propensión a fracasar de los emprendedores autónomos que ejercen su actividad en dicha comunidad.

\section{METODOLOGÍA}

A lo largo de las últimas décadas, algunos de los mayores avances de la literatura en fracaso empresarial han surgido a través de las metodologías de modelización. En este sentido, a partir de la década de los setenta del siglo 
pasado se popularizó el uso de metodologías basadas en los modelos de regresión logística. Su adecuación a la explicación de variables dicotómicas, como el evento de fracaso empresarial, y a la estimación de probabilidades, así como la sencillez de interpretación, popularizó la metodología hasta ser ampliamente utilizada en los análisis del fracaso empresarial. Así pues, la regresión logística binaria ha sido utilizada por multitud de autores como Ohlson (1980), Laffarga, Martín y Vázquez (1987), Somoza (2001) o Pozuelo, Labatut y Veres (2013), mientras que otros investigadores han optado por opciones más complejas como los modelos multilogit (Arquero, Abad y Jiménez, 2008), logit multiperiodos (Beaver, McNichols y Rhie, 2005; Beaver, Correia y McNichols, 2009) o modelos de regresión logística mixta (Jones y Hensher, 2004).

Este trabajo se basa en la metodología de regresión logística multinivel, variedad de la regresión logística binaria que permite tener en cuenta, a la hora de explicar el fracaso empresarial, distintos niveles de influencia, tal y como se desarrolla en el apartado 4.2.

\subsection{Muestra}

La muestra utilizada para estimar el modelo de fracaso de los autónomos se basa en los ficheros de microdatos de la Encuesta de Población Activa (EPA en adelante) que proporciona el Instituto Nacional de Estadística.

La EPA es una encuesta trimestral dirigida a alrededor de 65.000 viviendas familiares (hogares) de todo el territorio español, de forma que, aunque el cuestionario lo cumplimenta un miembro del hogar, se obtiene información sobre todos y cada uno de los integrantes del mismo, independientemente de su edad o situación respecto a la actividad económica (Garrido, Requena y Toharia, 2000). Por lo tanto, a la hora de construir la muestra de estudio se ha podido disponer de información sobre la "persona principal" del hogar y sobre el resto de los integrantes del mismo (aproximadamente 160.000 por trimestre).

Partiendo de la riqueza que aporta esta base de datos, se ha centrado el estudio en las personas de referencia de cada hogar cuya actividad profesional es ser empresario con o sin asalariados o trabajador independiente y que llevan ejerciendo su actividad durante doce meses o más o que, habiendo ejercido como empresarios con o sin asalariados o trabajadores independientes hace un año como mínimo, se encuentran en la actualidad en situación de desempleo. La muestra filtra, por lo tanto, aquellos empresarios autónomos que han abandonado su actividad durante el último año para pasar a una situación de inactividad por causa de jubilación o incapacidad permanente. 
A partir del ámbito señalado, el periodo de referencia son los cuartos trimestres de cada año desde 2008 a 2017, de forma que se recoge información completa para la evolución de la situación profesional de los empresarios autónomos de cada año natural, a la vez que permite recoger un periodo de crisis económica junto con otro de recuperación. Este hecho que permite realizar un análisis a lo largo del ciclo económico y evita caer en sesgos provocados por recoger una única fase del ciclo.

Por lo tanto, la muestra se compone de un total de 57.008 registros, de los cuales 2.470 han entrado en situación de fracaso durante un año (Tabla 6). Cabe destacar, dada la naturaleza del enfoque aplicado en el estudio, que se han filtrado los casos de Ceuta y Melilla. La razón de esta decisión se debe a la dificultad de comparar las realidades institucionales y macroeconómicas de ambas ciudades autónomas con las relativas a las comunidades autónomas, lo que habría producido sesgos en los resultados. No obstante, la importancia relativa de los casos filtrados es pequeña, de forma que sólo se ha visto afectado un $0,42 \%$ de la muestra.

Tabla 6: Muestra de construcción del modelo: casos por año y comunidad autónoma

\begin{tabular}{|c|c|c|c|c|c|c|c|c|c|c|c|}
\hline & & 2008 & 2009 & 2010 & 2011 & 2012 & 2013 & 2014 & 2015 & 2016 & 2017 \\
\hline \multirow{2}{*}{ Andalucía } & Total & 978 & 888 & 837 & 822 & 825 & 756 & 771 & 802 & 796 & 816 \\
\hline & Fracaso & 42 & 43 & 38 & 61 & 64 & 61 & 44 & 50 & 50 & 38 \\
\hline \multirow{2}{*}{ Aragón } & Total & 322 & 299 & 284 & 264 & 268 & 255 & 263 & 269 & 293 & 302 \\
\hline & Fracaso & 6 & 6 & 9 & 14 & 10 & 6 & 9 & 13 & 8 & 9 \\
\hline \multirow{2}{*}{ Asturias } & Total & 137 & 144 & 128 & 158 & 167 & 192 & 159 & 150 & 155 & 156 \\
\hline & Fracaso & 3 & 6 & 3 & 5 & 6 & 11 & 3 & 9 & 2 & 6 \\
\hline \multirow{2}{*}{$\begin{array}{l}\text { Islas } \\
\text { Baleares }\end{array}$} & Total & 170 & 158 & 153 & 147 & 183 & 177 & 180 & 172 & 160 & 149 \\
\hline & Fracaso & 11 & 9 & 7 & 12 & 17 & 19 & 10 & 12 & 6 & 5 \\
\hline \multirow{2}{*}{$\begin{array}{l}\text { Islas } \\
\text { Canarias }\end{array}$} & Total & 209 & 218 & 190 & 177 & 190 & 183 & 169 & 174 & 171 & 185 \\
\hline & Fracaso & 5 & 11 & 13 & 11 & 13 & 15 & 16 & 9 & 12 & 5 \\
\hline \multirow{2}{*}{ Cantabria } & Total & 178 & 158 & 134 & 139 & 159 & 142 & 127 & 143 & 129 & 117 \\
\hline & Fracaso & 5 & 7 & 4 & 4 & 7 & 10 & 7 & 1 & 1 & 4 \\
\hline \multirow{2}{*}{$\begin{array}{l}\text { Castilla y } \\
\text { León }\end{array}$} & Total & 693 & 656 & 604 & 624 & 653 & 690 & 607 & 616 & 631 & 588 \\
\hline & Fracaso & 20 & 24 & 22 & 23 & 33 & 25 & 28 & 16 & 12 & 11 \\
\hline \multirow{2}{*}{$\begin{array}{l}\text { Castilla La } \\
\text { Mancha }\end{array}$} & Total & 402 & 413 & 450 & 407 & 429 & 392 & 353 & 392 & 425 & 425 \\
\hline & Fracaso & 9 & 16 & 23 & 14 & 20 & 15 & 13 & 18 & 16 & 11 \\
\hline \multirow{2}{*}{ Cataluña } & Total & 813 & 667 & 663 & 603 & 603 & 636 & 651 & 672 & 629 & 610 \\
\hline & Fracaso & 28 & 33 & 26 & 25 & 34 & 27 & 26 & 25 & 14 & 21 \\
\hline \multirow{2}{*}{$\begin{array}{l}\text { Comunidad } \\
\text { Valenciana }\end{array}$} & Total & 522 & 496 & 469 & 451 & 420 & 414 & 442 & 470 & 406 & 443 \\
\hline & Fracaso & 20 & 35 & 15 & 30 & 28 & 28 & 27 & 21 & 21 & 17 \\
\hline \multirow{2}{*}{$\begin{array}{l}\text { Extrema- } \\
\text { dura }\end{array}$} & Total & 225 & 202 & 202 & 150 & 156 & 197 & 211 & 196 & 185 & 208 \\
\hline & Fracaso & 5 & 7 & 7 & 6 & 12 & 13 & 5 & 11 & 8 & 10 \\
\hline \multirow{2}{*}{ Galicia } & Total & 426 & 813 & 760 & 790 & 809 & 753 & 695 & 675 & 706 & 692 \\
\hline & Fracaso & 5 & 19 & 22 & 26 & 35 & 49 & 42 & 25 & 20 & 37 \\
\hline
\end{tabular}




\begin{tabular}{|c|c|c|c|c|c|c|c|c|c|c|c|}
\hline & & 2008 & 2009 & 2010 & 2011 & 2012 & 2013 & 2014 & 2015 & 2016 & 2017 \\
\hline \multirow{2}{*}{$\begin{array}{l}\text { Comunidad } \\
\text { de Madrid }\end{array}$} & Total & 220 & 234 & 239 & 214 & 236 & 207 & 194 & 202 & 233 & 230 \\
\hline & Fracaso & 7 & 11 & 9 & 12 & 9 & 16 & 7 & 11 & 14 & 6 \\
\hline \multirow{2}{*}{$\begin{array}{l}\text { Región de } \\
\text { Murcia }\end{array}$} & Total & 209 & 188 & 188 & 172 & 174 & 158 & 174 & 163 & 150 & 159 \\
\hline & Fracaso & 7 & 10 & 11 & 5 & 10 & 7 & 8 & 5 & 5 & 4 \\
\hline \multirow{2}{*}{$\begin{array}{l}\text { Comunidad } \\
\text { Foral de } \\
\text { Navarra } \\
\end{array}$} & Total & 149 & 157 & 141 & 145 & 142 & 128 & 142 & 111 & 103 & 124 \\
\hline & Fracaso & 5 & 4 & 3 & 5 & 6 & 10 & 3 & 3 & 1 & 4 \\
\hline \multirow{2}{*}{ País Vasco } & Total & 277 & 236 & 229 & 262 & 233 & 252 & 225 & 253 & 218 & 214 \\
\hline & Fracaso & 4 & 6 & 10 & 3 & 6 & 9 & 14 & 7 & 9 & 13 \\
\hline \multirow{2}{*}{ La Rioja } & Total & 119 & 115 & 103 & 122 & 128 & 125 & 92 & 99 & 126 & 116 \\
\hline & Fracaso & 3 & 2 & 5 & 5 & 3 & 6 & 2 & 3 & 2 & 3 \\
\hline \multirow{2}{*}{$\begin{array}{l}\text { Total de la } \\
\text { muestra }\end{array}$} & Total & 6.049 & 6.042 & 5.774 & 5.647 & 5.775 & 5.657 & 5.455 & 5.559 & 5.516 & 5.534 \\
\hline & Fracaso & 185 & 249 & 227 & 261 & 313 & 327 & 264 & 239 & 201 & 204 \\
\hline \multicolumn{12}{|c|}{ Filtros realizados } \\
\hline \multirow{2}{*}{ Ceuta } & Total & 18 & 12 & 10 & 9 & 13 & 12 & 14 & 19 & 17 & 13 \\
\hline & Fracaso & 1 & 0 & 0 & 1 & 1 & 2 & 1 & 2 & 3 & 0 \\
\hline \multirow{2}{*}{ Melilla } & Total & 13 & 15 & 15 & 11 & 10 & 6 & 8 & 17 & 15 & 13 \\
\hline & Fracaso & 0 & 0 & 0 & 0 & 0 & 0 & 0 & 2 & 0 & 0 \\
\hline
\end{tabular}

Fuente: Elaboración propia

\subsection{Regresión Logística Multinivel}

Los modelos más usuales que se observan en la literatura sobre fracaso empresarial a lo largo de las últimas décadas se basan, con mayor o menor complejidad, en la regresión logística. Sin embargo, los modelos de regresión logística más clásicos no tienen en cuenta la estructura jerárquica de los datos, es decir, que las observaciones individuales suelen pertenecer a colectivos que tienen características comunes y, por lo tanto, dichas observaciones no son totalmente independientes entre sí. La metodología de análisis logístico multinivel permite superar esta limitación y profundizar en las diferencias que se observan dentro de los colectivos. En el contexto de este trabajo, los empresarios autónomos tienen características propias basadas en sus características socioeconómicas, pero también se ven condicionados por las condiciones macroeconómicas e institucionales de las regiones en donde desarrollan su actividad, principalmente en países como España, con un fuerte componente de descentralización.

Por lo tanto, los modelos de regresión logística multinivel son adecuados para el análisis de fenómenos dicotómicos (fracasar o no, en este caso) bajo una perspectiva regional, pues tiene en cuenta tanto las características individuales de los empresarios como las correlaciones intrarregionales. 
Desde un punto de vista formal, y adaptado al contexto del trabajo, en la muestra de desarrollo se pueden distinguir dos niveles: el nivel 1 compuesto por los empresarios autónomos $(i)$ y el nivel 2 compuesto por las Comunidades Autónomas ( $j$ ). Bajo este marco, el objetivo es explicar el fenómeno del fracaso emprendedor de los empresarios autónomos $\left(\mathrm{Y}_{\mathrm{ij}}\right)$, por lo que la variable dependiente tomará el valor 1 en caso de fracaso y el valor 0 en caso de supervivencia. Los factores explicativos son múltiples, pero por simplificación se asume en la explicación una única variable independiente, de forma que la expresión para el i-ésimo individuo (nivel 1) que se encuentra dentro de la jésima región (nivel 2) sería la siguiente:

$$
Y_{i j}=\beta_{o j}+\beta_{1 j} X_{i j}+e_{i j}
$$

Siendo $\beta_{o j}$ la constante, $\beta_{1 j}$ la pendiente de la variable explicativa $X_{i j}$ y $e_{i j}$ es la variación residual del i-ésimo empresario autónomo que desarrolla su actividad en la j-ésima región.

Al pretender considerar ambos niveles jerárquicos dentro del mismo modelo y conocer la variabilidad causada por el segundo nivel, los coeficientes pasan a ser variables aleatorias en el segundo nivel, tal y como se refleja a continuación:

$$
\begin{aligned}
& \beta_{0 j}=\beta_{0}+\mu_{o j} \\
& \beta_{1 j}=\beta_{1}+\mu_{1 j}
\end{aligned}
$$

Por lo tanto, la constante se descompone en dos partes: $\beta_{o}$ que se refiere al fracaso medio de los emprendedores autónomos en el país y $\mu_{o j}$ que se refiere a la varianza de las constantes de las diferentes regiones, representando la parte aleatoria del modelo en el nivel 2. A su vez $\beta_{1 j}$ se descompone en $\beta_{1}$, referido al nivel medio del país para la variable $X_{i j}$ y $\mu_{i j}$ que muestra la variabilidad de los coeficientes de regresión para la variable $X_{i j}$ y las distintas regiones, siendo la parte aleatoria del modelo en el nivel 2 vinculada a la pendiente de la variable $X_{i j}$.

Por lo tanto, la expresión (1) se podría expresar de la siguiente manera:

$$
Y_{i j}=\beta_{o}+\beta_{1} X_{i j}+\left(\mu_{0 j}+\mu_{1 j} X_{i j}+e_{i j}\right)
$$

Siendo la parte aleatoria la que está dentro del paréntesis y la parte fija el resto. 


\section{DEFINICIÓN DE LAS VARIABLES Y DATOS UTILIZADOS}

Una vez descrita la muestra de desarrollo del modelo y la perspectiva metodológica, se procede a definir las variables dependientes e independientes y describir las fuentes de datos utilizadas y el proceso de construcción.

\subsection{El fracaso emprendedor como variable dependiente}

Dada la naturaleza del modelo, la variable dependiente del modelo tiene una naturaleza dicotómica:

- 1: El empresario autónomo ha fracasado a lo largo de los últimos doce meses, estando en la actualidad en situación de desempleo.

- 0: El empresario autónomo continúa ejerciendo su actividad, que lleva ejerciendo durante doce meses o más.

Dicha variable se ha construido con los microdatos de la EPA, que aporta información a nivel hogar, teniendo en cuenta los datos de todos los miembros de la vivienda.

Por lo tanto, se considera empresario autónomo a aquellas personas que tienen un negocio, independientemente del tamaño, que contratan o no a otros profesionales o que trabajan de forma independiente.

Con el fin de construir la variable, en primer lugar, se ha identificado a la persona de referencia, teniendo en cuenta las dos siguientes casuísticas posibles:

- Para aquellas personas que mantienen su actividad en la semana de referencia (Fecha en la que se lleva a cabo la EPA.), la situación profesional debe ser "Empresario con asalariados" o "Trabajador independiente o empresario sin asalariados". Además, se impone que dichos empresarios hayan ejercido su actividad a lo largo de un mínimo de doce meses.

- En el caso de las personas que han abandonado su actividad a lo largo de los últimos doce meses, la última situación profesional debe haber sido "Empresario con asalariados" o "Trabajador independiente o empresario sin asalariados". En este sentido, se considera como abandono el haber ejercicio una actividad empresarial que ha finalizado en los últimos doce meses, estando la persona en situación de desempleo en la semana 
de referencia. Por ello, se descartan los casos que se encuentran en situación de inactividad, como es la jubilación o la incapacidad permanente, o que estén trabajando en la semana de análisis.

En definitiva, se estudia el abandono de la actividad emprendedora a lo largo de los últimos doce meses, considerando, por lo tanto, el abandono temprano de la actividad emprendedora, en términos coherentes con la praxis de la gestión del riesgo de crédito de las entidades financieras (Acuerdos de Basilea y marco contable IFRS 9). La tabla 7 muestra la distribución de la variable dependiente por Comunidad Autónoma y permite ver las diferencias, a nivel descriptivo, que parecen existir en términos regionales:

\subsection{Variables explicativas}

Una vez descrita la definición y proceso de construcción de la variable dependiente, corresponde en este apartado hacer lo mismo con las distintas variables explicativas. En este caso, el análisis se realizará en dos niveles, según se trate de variables referentes a las características socioeconómicas de los empresarios o a variables de nivel regional, consistentes en factores macroeconómicos o institucionales.

Tabla 7: Tasa de fracaso media por Comunidad Autónoma

\begin{tabular}{|c|c|c|c|c|c|c|c|c|}
\hline Andalucía & Aragón & Asturias & $\begin{array}{c}\text { Islas } \\
\text { Baleares }\end{array}$ & $\begin{array}{c}\text { Islas } \\
\text { Canarias }\end{array}$ & Cantabria & $\begin{array}{c}\text { Castilla y } \\
\text { León }\end{array}$ & $\begin{array}{c}\text { C. La } \\
\text { Mancha }\end{array}$ & Cataluña \\
\hline $5,92 \%$ & $3,19 \%$ & $3,49 \%$ & $6,55 \%$ & $5,89 \%$ & $3,51 \%$ & $3,36 \%$ & $3,79 \%$ & $3,96 \%$ \\
\hline $\begin{array}{c}\text { Comunidad } \\
\text { Valenciana }\end{array}$ & $\begin{array}{c}\text { Extrema- } \\
\text { dura }\end{array}$ & Galicia & $\begin{array}{c}\text { Comunidad } \\
\text { de Madrid }\end{array}$ & Murcia & Navarra & $\begin{array}{c}\text { País } \\
\text { Vasco }\end{array}$ & $\begin{array}{c}\text { La } \\
\text { Rioja }\end{array}$ & $\begin{array}{c}\text { Total } \\
\text { muestra }\end{array}$ \\
\hline $5,34 \%$ & $4,35 \%$ & $3,93 \%$ & $4,62 \%$ & $4,15 \%$ & $3,28 \%$ & $3,38 \%$ & $2,97 \%$ & $4,33 \%$ \\
\hline
\end{tabular}

Fuente: Elaboración propia. Datos de los microdatos de la EPA.

6.2.1. Variables representativas de las características socioeconómicas de los empresarios

- El empresario crea empleo: Variable dicotómica que toma el valor $S i$ en el caso de que el empresario tenga trabajadores a su cargo y No en el caso contrario, tanto para el caso de que el empresario siga ejerciendo su actividad como para el caso contrario. 
- Sexo de la persona: Variable dicotómica que, para la persona de referencia, toma los valores Mujer y Varón.

- Sector de actividad: Variable categórica que señala el sector de actividad del empresario y que toma los siguientes valores:

- Primario: Se incluye los sectores de la agricultura, ganadería, silvicultura y pesca (códigos CNAE-09: 01, 02 y 03).

- Industrial: Se incluyen los sectores de la industria de la alimentación, textil, cuero, madera y papel (códigos CNAE-09: del 10 al 18), las industrias extractivas, refino de petróleo, industria química, farmacéutica, industria del caucho y materias plásticas, suministro energía eléctrica, gas, vapor $\mathrm{y}$ aire acondicionado, suministro de agua, gestión de residuos, metalurgia (códigos CNAE-09: del 05 al 09, del 19 al 25, 35 y del 36 al 39), así como los sectores de la construcción de maquinaria, equipo eléctrico y material de transporte. Instalación y reparación industrial (códigos CNAE09 del 26 al 33).

- Construcción: Incluye las actividades de construcción (códigos CNAE09: del 41 al 43).

- Distribución comercial: Se incluyen las actividades de comercio al por mayor y al por menor y sus instalaciones y reparaciones, reparación de automóviles y hostelería (códigos CNAE-09: del 45 al 47, 55 y 56).

- Resto de servicios: Incluye el transporte y almacenamiento, la información y comunicaciones (códigos CNAE-09 del 49 al 53 y del 58 al 63), la intermediación financiera, seguros, actividades inmobiliarias, servicios profesionales, científicos, administrativos y otros (códigos CNAE-09: del 64 al 66, 68, del 69 al 75 y del 77 al 82), la Administración Pública, educación y actividades sanitarias (códigos CNAE-09: 84, 85 y del 86 al 88), así como otros servicios (códigos CNAE-09: del 90 al 93, del 94 al $96,97 y$ 99).

- Indicador que señala si el cónyuge tiene empleo o no: Variable categórica construida a partir de los datos concernientes al cónyuge de la persona principal según la relación de parentesco con la persona de referencia que informa la EPA. De esta forma, si el cónyuge tiene una actividad profesional propia, la variable toma el valor $S i$. En caso contrario, el valor será No. Si la persona de referencia no tuviera cónyuge, la variable toma el valor No tiene cónyuge. 
- Edad del empresario: Variable categórica construida a partir de los datos de edad de la persona de referencia, habiendo definido las siguientes categorías:

- De 16 a 34 años: La persona principal tiene de 16 a 34 años.

- De 35 a 44 años: La persona principal tiene de 35 a 44 años.

- De 45 a 59 años: La persona principal tiene de 45 a 59 años.

- Más de 60 años: La persona principal tiene más de 60 años.

- Estado civil de la persona de referencia: Variable categórica que señala el estado civil de la persona de referencia, tomando las siguientes categorías:

- Separado o divorciado: Si la persona de referencia está separado o divorciado.

- Casado: Si la persona de referencia se encuentra casado.

- Soltero o viudo: Si la persona de referencia se encuentra soltero viudo.

- Edad máxima de fin de estudios: Variable continua que muestra la edad en la que la persona de referencia alcanzó el máximo nivel de estudios. Si esta variable no está informada, porque no se conoce el dato, se le imputa el valor mínimo de la muestra, que es 7 .

- Indicador de hijos: Variable dicotómica que señala si la persona de referencia tiene hijos a su cargo (valor $\mathrm{Si}$ ) o no (valor $\mathrm{No}$ ).

La tabla 8 presenta la distribución y la tasa de fracaso de las variables anteriormente presentadas, según sean categóricas o continuas.

\subsubsection{Variables macroeconómicas}

Con el fin de analizar la influencia del entorno macroeconómico en el fracaso de la actividad emprendedora de los autónomos, se han utilizado y calculado las variables que se describen a continuación y que reflejan distintas perspectivas (económica y financiera) de la realidad regional española:

- Tasa de variación interanual del Producto Interior Bruto (en volúmenes encadenados) por Comunidad Autónoma: Dato obtenido de la Contabilidad regional de España para cada Comunidad Autónoma en el periodo seleccionado.

- Tasa de paro por Comunidad Autónoma: Dato obtenido de la Encuesta de Población Activa para cada Comunidad Autónoma en el periodo seleccionado. 
Tabla 8: Tasa de fracaso de las variables socioeconómicas

\begin{tabular}{|c|c|c|c|c|}
\hline Variable & Categoría & Total & Fracaso & Tasa de fracaso \\
\hline \multirow{2}{*}{ Crea empleo } & Sí & 19.896 & 387 & $1,9 \%$ \\
\hline & No & 37.112 & 2.083 & $5,6 \%$ \\
\hline \multirow{2}{*}{ Hijos } & Sí & 21.319 & 823 & $3,9 \%$ \\
\hline & No & 35.689 & 1647 & $4,6 \%$ \\
\hline \multirow[b]{2}{*}{ Sexo } & Mujer & 15.813 & 938 & $5,9 \%$ \\
\hline & Varón & 41.195 & 1.532 & $3,7 \%$ \\
\hline \multirow{5}{*}{ Sector } & Primario & 7.183 & 162 & $2,26 \%$ \\
\hline & Industria & 5.268 & 171 & $3,25 \%$ \\
\hline & Construcción & 7.355 & 532 & $7,23 \%$ \\
\hline & Distribución comercial & 19.595 & 954 & $4,87 \%$ \\
\hline & Resto de servicios & 17.607 & 651 & $3,70 \%$ \\
\hline \multirow{3}{*}{$\begin{array}{l}\text { Empleo del } \\
\text { cónyuge }\end{array}$} & Sí & 31.345 & 955 & $3,0 \%$ \\
\hline & No & 13.213 & 805 & $6,1 \%$ \\
\hline & No tiene cónyuge & 12.450 & 710 & $5,7 \%$ \\
\hline \multirow{4}{*}{ Edad } & De 16 a 34 años & 4.444 & 317 & $7,1 \%$ \\
\hline & De 35 a 44 años & 14.715 & 704 & $4,78 \%$ \\
\hline & De 45 a 59 años & 29.254 & 1.085 & $3,7 \%$ \\
\hline & Más de 60 años & 8.595 & 364 & $4,24 \%$ \\
\hline \multirow{4}{*}{ Estado civil } & Separado o divorciado & 4.561 & 310 & $6,8 \%$ \\
\hline & Casado & 41.518 & 1.524 & $3,7 \%$ \\
\hline & Soltero o viudo & 10.929 & 636 & $5,8 \%$ \\
\hline & & \multicolumn{2}{|c|}{$\begin{array}{c}\text { Empresarios } \\
\text { supervivientes }\end{array}$} & $\begin{array}{c}\text { Empresarios no } \\
\text { supervivientes }\end{array}$ \\
\hline \multirow{6}{*}{$\begin{array}{c}\text { Edad máxima de } \\
\text { estudios }\end{array}$} & Media & \multicolumn{2}{|c|}{18,61104184} & 18,14331984 \\
\hline & Mediana & \multicolumn{2}{|c|}{17} & 16 \\
\hline & Moda & \multicolumn{2}{|c|}{14} & 14 \\
\hline & Desviación estándar & \multicolumn{2}{|c|}{5,99615433} & 6,525249733 \\
\hline & Mínimo & \multicolumn{2}{|c|}{7} & 7 \\
\hline & Máximo & \multicolumn{2}{|c|}{67} & 60 \\
\hline
\end{tabular}

Fuente: Elaboración propia

- Deuda pública autonómica como porcentaje del PIB: Dato obtenido del Boletín Estadístico del Banco de España, según el Procedimiento de Déficit Excesivo.

- Tasa de variación interanual del crédito: Dato construido a partir de la información obtenida del Boletín Estadístico del Banco de España y de la Asociación Española de Banca. 
- Variación de la presión fiscal autonómica: Variación interanual del indicador de presión fiscal, construido para este trabajo en base a información pública para cada Comunidad Autónoma, según la expresión siguiente:

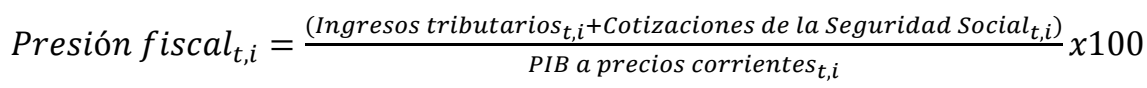

Siendo $t$ el año e $i$ la Comunidad Autónoma.

Los ingresos tributarios se han obtenido del Informe Anual de Recaudación Tributaria correspondiente a cada año y Comunidad Autónoma, publicado por la Agencia Tributaria. Los impuestos y conceptos incluidos en la contabilización de ingresos son los siguientes:

- Impuesto sobre la Renta de las Personas Físicas.

- Impuesto sobre Sociedades.

- Impuesto sobre la Renta de No Residentes.

- Impuestos medioambientales.

- Declaración tributaria especial.

- Impuesto sobre sucesiones y donaciones.

- Impuesto sobre el patrimonio.

- Impuesto sobre el Valor Añadido.

- Impuestos Especiales: Alcohol y bebidas derivadas, Cerveza, Productos intermedios, Hidrocarburos, Labores del tabaco, Electricidad, Carbón, Otros, Participación de las AA.TT.

- Impuesto sobre primas de seguros.

- Tráfico exterior.

- Impuesto actividades juego.

- Impuesto sobre gases fluorados.

- Tasa radioeléctrica.

- Canon de aguas.

- Otras tasas.

- Recargos, intereses y sanciones tributarias.

Por su parte, la información concerniente a las cotizaciones de la seguridad se ha obtenido de las Cuentas del Sistema de la Seguridad Social, (Liquidación del Presupuesto de Recursos y Aplicaciones del total Sistema de la Seguridad Social), dentro del Anuario de estadísticas del Ministerio de Trabajo, Migraciones y Seguridad Social. 
Los datos de cotizaciones se refieren a las operaciones corrientes de los siguientes regímenes (tanto cuotas de empleadores como cuotas de trabajadores): Régimen General, Régimen Especial para la Minería del Carbón, Régimen Especial de los Trabajadores Autónomos, Régimen Especial Agrario, Régimen Especial de los Trabajadores del Mar, Régimen Especial de los Empleados de Hogar.

También se incluyen las cotizaciones por: Accidentes de Trabajo y Enfermedades Profesionales (Instituto Nacional de Seguridad Social y Mutuas), Cotización de Desempleados Cese Actividad y Bonificaciones (a carago del Servicio Público de Empleo Estatal y de las Mutuas colaboradoras de la Seguridad Social) y las Cotizaciones Cese Actividades de los Trabajadores Autónomos.

Como no se dispone de la información de cotizaciones a nivel regional, se ha calculado una aproximación, mediante un factor lineal, en base al dato de afiliados por Comunidad Autónoma, tal y como muestra la siguiente expresión:

$$
\text { Cotizaciones }_{t, i}=\text { Cotizaciones }_{t} \times \frac{\text { Afiliados en situación de alta laboral }}{t, i}
$$

Siendo $t$ el año e $i$ la Comunidad Autónoma. Dicha información relativa a los trabajadores afiliados se ha obtenido del Anuario de estadísticas del Ministerio de Trabajo, Migraciones y Seguridad Social.

La distribución media de las variables de índole macroeconómica descritas se encuentra contenida en la tabla 9:

Tabla 9: Distribución general de las variables macroeconómicas e institucionales ${ }^{4}$

\begin{tabular}{|l|r|r|r|r|r|r|}
\hline & \multicolumn{1}{|c|}{ Media } & Mediana & \multicolumn{1}{c|}{ Moda } & $\begin{array}{c}\text { Desv. } \\
\text { Estándar }\end{array}$ & Mínimo & Máximo \\
\hline Variación PIB & 0,00108 & 0,00289 & 0,0064 & 0,02584 & $-0,0561$ & 0,06233 \\
\hline Tasa de paro & 0,19973 & 0,1916 & 0,2077 & 0,06672 & 0,0663 & 0,3622 \\
\hline Deuda pública & 0,1742 & 0,164 & 0,086 & 0,0942 & 0,015 & 0,427 \\
\hline Variación Crédito & $-0,0141$ & $-0,02421$ & 0,029039 & 0,12917 & $-0,6089$ & 1,35004 \\
\hline Variación Presión fiscal & $-0,0161$ & 0,000448 & $-0,17369$ & 0,07237 & $-0,4913$ & 0,29822 \\
\hline Carga regulación relativa & 0,0676 & 0,0622 & 0,0634 & 0,0336 & 0,0065 & 0,1714 \\
\hline Transparencia & 83,9518 & 87,5 & 87,5 & 12,3671 & 53,8 & 100 \\
\hline Eficiencia de la justicia & 1,1773 & 1,1289 & 1,7799 & 0,2942 & 0,409 & 2,1151 \\
\hline
\end{tabular}

Fuente: Elaboración propia

\footnotetext{
${ }^{4}$ Se refleja en esta tabla el análisis descriptivo de las variables aplicadas a la muestra del modelo, sin distinguir por año o Comunidad Autónoma. Por esta razón, y para evitar conclusiones segadas, tampoco se distingue por muestra de fracaso o no fracaso.
} 


\subsubsection{Variables institucionales}

El objetivo, propuesto en este trabajo, de analizar la posible influencia de factores de índole institucional sobre la probabilidad de fracaso de los empresarios autónomos españoles lleva a la necesidad de utilizar o construir, en la medida de lo posible, magnitudes representativas de los principales ámbitos de influencia de las instituciones en la actividad empresarial. En este sentido, a continuación, se señalan las tres variables evaluadas y su metodología de construcción.

- Carga regulatoria relativa de las Comunidades Autónomas: Se ha construido un indicador relativo en el que se relaciona la carga regulatoria de cada Comunidad Autónoma con respecto del total de las Comunidades Autónomas.

Con el objetivo de medir dicha carga regulatoria, se han utilizado los datos de la CEOE (2016, 2017 y 2018) en relación con el número de páginas de los boletines oficiales de todas las Comunidades Autónomas.

- Índice de transparencia de las Comunidades Autónomas: Índice publicado por Transparencia Internacional España, que se distribuye entre 1 y 100 y que busca medir el nivel de transparencia a través de la información pública de las páginas web de las instituciones evaluadas en base a múltiples indicadores (Transparencia Internacional España, 2016).

El índice está publicado para los años 2010, 2012, 2014 y 2016. Por lo tanto, el problema que se ha encontrado al utilizar este índice es la falta de datos para los años en los que no está disponible. A este respecto, se han ajustado los datos de la siguiente manera:

- Ante la falta de información, se asume el valor de 2010 para los años 2008 y 2009.

- Igualmente, a causa de la falta de datos más recientes, se asume el valor de 2016 para el año 2017.

- Para los años intermedios en los que no existe dato (2011, 2013 y 2015), se realiza una interpolación lineal en base a la siguiente expresión:

$$
y_{t}=y_{t-1}+\frac{\left(y_{t+1}-y_{t-1}\right) x\left(x_{t}-x_{t-1}\right)}{\left(x_{t+1}-x_{t-1}\right)}
$$


- Eficiencia de la justicia a nivel autonómico: En base a los datos de las estadísticas de juzgados y tribunales del Consejo General del Poder Judicial, recogidos en los "Informes por territorios sobre la actividad de los órganos judiciales", se han obtenido, para cada año y Comunidad Autónoma, los datos del número de asuntos en trámite tanto al inicio del año como al final del año, dentro del ámbito de los juzgados de lo Mercantil. De esta manera, se busca medir la eficiencia de la justicia mercantil comparando el número se asuntos abiertos al final del año con respecto al inicio del año, tal y como se refleja en la siguiente ratio:

$$
\text { Eficiencia de la justicia }=\frac{\text { Número de asuntos en trámite al final del ejercicio } o_{t, i}}{\text { Número de asuntos en trámite al inicio del ejercicio } o_{t, i}}
$$

Siendo $t$ el año en análisis e $i$ la Comunidad Autónoma. Por lo tanto, un factor superior a 1 refleja aumento de los trámites abiertos con respecto al inicio del ejercicio y, por lo tanto, una menor eficiencia de esa administración, ocurriendo lo contrario en caso de que el factor tome un valor por debajo de 1.

Asimismo, la tabla 9 refleja la distribución de las tres variables institucionales descritas.

\section{RESULTADOS}

El proceso de modelización se ha realizado en varias etapas. En primer lugar, se ha desarrollado el modelo de regresión logística multinivel teniendo en cuenta los efectos fijos de las variables relativas a las características socioeconómicas de los empresarios autónomos, a la vez que se ha contrastado la existencia de efectos aleatorios significativos a nivel Comunidad Autónoma. La tabla 10 recoge estos resultados, diferenciando entre los efectos fijos y el modelo de constante aleatoria. En segundo lugar, al confirmar la hipótesis de diferencias regionales, se procede a estimar los modelos incluyendo, dentro de la parte de efectos fijos, variables de segundo nivel de naturaleza macroeconómica e institucional que permitan aportar capacidad explicativa. Adicionalmente, la hipótesis de especialización sectorial definida en este trabajo se contrastará a través de la inclusión de la variable sector no sólo en la parte de los efectos fijos, sino también en la parte aleatoria del modelo, contrastando si el sector explica parte de las diferencias regionales encontradas. 
Tabla 10: Modelo de regresión logística multinivel de efectos fijos (características socioeconómicas de los empresarios) y constante aleatoria

\begin{tabular}{|c|c|c|c|c|c|}
\hline Variable & Categoría & Coeficiente & $\begin{array}{l}\text { Desv. } \\
\text { Error }\end{array}$ & $\begin{array}{l}\text { Prob. } \\
\text { Sig. }\end{array}$ & $\begin{array}{l}\text { Odd } \\
\text { ratio }\end{array}$ \\
\hline Intersección & & $-0,829$ & 0,1293 & 0,000 & 0,437 \\
\hline Crea empleo (Ref.: No) & Sí & $-1,153$ & 0,0569 & 0,000 & 0,316 \\
\hline Sexo (Ref.: Mujer) & Varón & $-0,629$ & 0,0485 & 0,000 & 0,533 \\
\hline \multirow{4}{*}{$\begin{array}{c}\text { Sector } \\
\text { (Ref.: Construcción) }\end{array}$} & Resto de servicios & $-0,973$ & 0,0667 & 0,000 & 0,378 \\
\hline & Primario & $-1,450$ & 0,0951 & 0,000 & 0,235 \\
\hline & Industria & $-0,789$ & 0,0919 & 0,000 & 0,454 \\
\hline & Distribución comercial & $-0,603$ & 0,0613 & 0,000 & 0,547 \\
\hline Hijos (Ref.: No) & Sí & $-0,011$ & 0,0509 & 0,836 & 0,990 \\
\hline \multirow{2}{*}{$\begin{array}{c}\text { Empleo cónyuge } \\
\text { (Ref.: No) }\end{array}$} & Sí & $-0,745$ & 0,0512 & 0,000 & 0,475 \\
\hline & No tiene cónyuge & $-0,570$ & 0,0788 & 0,000 & 0,565 \\
\hline \multirow{3}{*}{$\begin{array}{c}\text { Edad } \\
\text { (Ref.: De } 16 \text { a 34) }\end{array}$} & Más de 60 & $-0,461$ & 0,0863 & 0,000 & 0,631 \\
\hline & De 44 a 59 & $-0,514$ & 0,0749 & 0,000 & 0,598 \\
\hline & De 35 a 44 & $-0,301$ & 0,0733 & 0,000 & 0,740 \\
\hline \multirow{2}{*}{$\begin{array}{c}\text { Estado civil } \\
\text { (Ref.: Casado) }\end{array}$} & Soltero o viudo & 0,431 & 0,0716 & 0,000 & 1,538 \\
\hline & Separado o divorciado & 0,629 & 0,0871 & 0,000 & 1,875 \\
\hline \multirow[t]{2}{*}{$\begin{array}{c}\text { Edad máxima de } \\
\text { estudios }\end{array}$} & & $-0,009$ & 0,0039 & 0,024 & 0,991 \\
\hline & & Estimación & $\begin{array}{l}\text { Desv. } \\
\text { Error }\end{array}$ & $\begin{array}{l}\text { Prob. } \\
\text { Sig. }\end{array}$ & \\
\hline $\begin{array}{c}\text { Varianza de los efectos } \\
\text { aleatorios }\end{array}$ & & 0,048 & 0,020 & 0,019 & \\
\hline
\end{tabular}

Fuente: Elaboración propia

Se puede apreciar en la tabla 10 que prácticamente todas las variables y categorías representativas de las características socioeconómicas de los emprendedores autónomos son estadísticamente significativas bajo un nivel de confianza del 95\%. La única excepción la constituye la variable Hijos, lo que permite concluir que el tener o no hijos no es un factor significativo en la probabilidad de fracasar como empresario autónomo, por lo que se rechaza la hipótesis 5 del trabajo, aceptándose, por lo tanto, las hipótesis 3, 4, 6, 7, 8 y 9 . En cuanto a los resultados, es destacable el hecho de que los empresarios que generan empleo tienen menos probabilidad de fracasar que los que no lo hacen. Posiblemente se debe a que contratan cuando tienen más consolidada su actividad, de formas que no se encuentran tan expuestos a la probabilidad de despedir y, por lo tanto, asumir el coste de dichos despidos. Asimismo, la probabilidad de fracasar es mayor entre las mujeres que entre los hombres, que reducen su probabilidad un $47 \%$ respecto a las primeras, de la misma forma que es más probable el fracaso entre los empresarios más jóvenes y con menos nivel de estudios, confirmando aportaciones previas de la literatura (Álvarez y Otero, 2006) y 
debiéndose, en parte, a la mayor inexperiencia de gestión y menor formación, especialmente en temas económico-empresariales, necesarios en el día a día de la gestión empresarial. En términos de edad, es destacable, a su vez, la probabilidad de fracaso decreciente con la edad salvo en el tramo de más de 60 años, en donde la probabilidad aumenta con respecto al tramo anterior y siempre tomando como referencia el tramo de mayor juventud.

En cuanto a las variables más relacionadas con la familia, la mayor probabilidad de fracaso se da entre los empresarios solteros o divorciados, suponiendo un $87,5 \%$ más de probabilidad con respecto a un empresario casado, mientras que, dentro de este último grupo, los empresarios cuyo cónyuge no tiene ningún empleo tienen la mayor probabilidad de abandonar su actividad, reduciéndose un 52,5\% en el caso de que sí tengan otro empleo, debido, probablemente, al apoyo que supone en términos de actividad, sino también financieros (avales u otras garantías, por ejemplo).

Por último, en cuanto a la influencia del sector de actividad, la mayor probabilidad de fracaso se observa en el sector de la construcción, siendo los sectores con menor probabilidad los relativos a las actividades del sector primario y los servicios no relacionados con la distribución comercial.

Por otra parte, dada la significatividad estadística de la varianza de los efectos aleatorios, se puede concluir que existen diferencias a nivel regional que no recogen las variables de efectos fijos (hipótesis 1), por lo que se procede a estimar los modelos incluyendo las variables macroeconómicas e institucionales (nivel 2) en la parte de efectos fijos para confirmar si se cumplen las hipótesis del trabajo y capturan la razón de las diferencias entre las Comunidades Autónomas. Por otra parte, se decide incluir, dentro de la parte aleatoria, el sector de actividad, de forma que se busca confirmar la hipótesis de especialización productiva de las regiones.

Así pues, los resultados mostrados en las tablas 11 y 12 resultan muy ilustrativos. En primer lugar, se confirman todas las hipótesis de influencia de las variables macroeconómicas estudiadas (hipótesis 10 a 14), pues su coeficiente resulta estadísticamente significativo. De esta forma, la probabilidad de fracasar de un empresario autónomo es mayor cuanto menor sea el crecimiento del PIB y del crédito bancario y cuanto mayor sea la tasa de desempleo, la deuda pública y el crecimiento de la presión fiscal. En segundo lugar, el sector de actividad resulta significativo en la parte aleatoria de todos los modelos, lo que confirma la hipótesis de diferencias en la especialización sectorial de las regiones y en su influencia en la probabilidad de fracasar de los empresarios autónomos (hipótesis 2). Por último, también se debe destacar la inclusión de las variables macroeconómicas en la parte aleatoria del modelo no han resultado significativas, salvo en el caso del crecimiento del crédito, lo que permite inferir 
que, a pesar de que la variable resulta significativa en la parte de los efectos fijos, existe evidencia de diferencias interregionales en el impacto del crédito en la probabilidad de fracasar no recogidas por la variable en los efectos fijos.

Tabla 11: Efectos fijos. Inclusión de variables macroeconómicas

\begin{tabular}{|c|c|c|c|c|c|c|}
\hline Variable & Categoría & Modelo 1 & Modelo 2 & Modelo 3 & Modelo 4 & Modelo 5 \\
\hline Intersección & & $\begin{array}{c}-0,891 * * * \\
(0,1354)\end{array}$ & $\begin{array}{c}-1,711 * * * \\
(0,1547)\end{array}$ & $\begin{array}{c}-0,961 * * * \\
(0,1381)\end{array}$ & $\begin{array}{c}-0,862 * * * \\
(0,1360)\end{array}$ & $\begin{array}{c}-0,821 * * * \\
(0,1350)\end{array}$ \\
\hline $\begin{array}{l}\text { Crea empleo } \\
\text { (Ref.: No) }\end{array}$ & Sí & $\begin{array}{c}-1,164 * * * \\
(0,0570)\end{array}$ & $\begin{array}{c}-1,140 * * * \\
(0,0570)\end{array}$ & $\begin{array}{c}-1,153 * * * \\
(0,0570)\end{array}$ & $\begin{array}{c}-1,151^{* * * *} \\
(0,0570)\end{array}$ & $\begin{array}{c}-1,157 * * * \\
(0,0570)\end{array}$ \\
\hline $\begin{array}{c}\text { Sexo } \\
\text { (Ref.: Mujer) }\end{array}$ & Varón & $\begin{array}{c}-0,619 * * * \\
(0,0486) \\
\end{array}$ & $\begin{array}{c}-0,630 * * * \\
(0,0486) \\
\end{array}$ & $\begin{array}{c}-0,628^{* * * *} \\
(0,0486) \\
\end{array}$ & $\begin{array}{c}-0,621 * * * \\
(0,0486) \\
\end{array}$ & $\begin{array}{c}-0,624 * * * \\
(0,0485) \\
\end{array}$ \\
\hline \multirow{4}{*}{$\begin{array}{c}\text { Sector } \\
\text { (Ref.: } \\
\text { Construcción) }\end{array}$} & $\begin{array}{l}\text { Resto de } \\
\text { servicios }\end{array}$ & $\begin{array}{c}-0,956^{* * *} \\
(0,0915)\end{array}$ & $\begin{array}{c}-0,968^{* * * *} \\
(0,0942)\end{array}$ & $\begin{array}{c}-0,970 * * * \\
(0,0914)\end{array}$ & $\begin{array}{c}-0,962 * * * \\
(0,0924)\end{array}$ & $\begin{array}{c}-0,965 * * * \\
(0,0913)\end{array}$ \\
\hline & Primario & $\begin{array}{c}-1,490 * * * \\
(0,1191)\end{array}$ & $\begin{array}{c}-1,510^{* * * *} \\
(0,1216)\end{array}$ & $\begin{array}{c}-1,494^{* * * *} \\
(0,1189) \\
\end{array}$ & $\begin{array}{c}-1,496^{* * *} \\
(0,1200)\end{array}$ & $\begin{array}{c}-1,493 * * * \\
(0,1189) \\
\end{array}$ \\
\hline & Industria & $\begin{array}{c}-0,791^{* * *} \\
(0,1130)\end{array}$ & $\begin{array}{c}-0,803^{* * * *} \\
(0,1155)\end{array}$ & $\begin{array}{c}-0,799^{* * *} \\
(0,1129) \\
\end{array}$ & $\begin{array}{c}-0,797 * * * \\
(0,1138) \\
\end{array}$ & $\begin{array}{c}-0,793^{* * * *} \\
(0,1128)\end{array}$ \\
\hline & $\begin{array}{c}\text { Distribución } \\
\text { comercial }\end{array}$ & $\begin{array}{c}-0,554 * * * \\
(0,0872)\end{array}$ & $\begin{array}{c}-0,567 * * * \\
(0,0899) \\
\end{array}$ & $\begin{array}{c}-0,567 * * * \\
(0,0871) \\
\end{array}$ & $\begin{array}{c}-0,560 * * * \\
(0,0881) \\
\end{array}$ & $\begin{array}{c}-0,563 * * * \\
(0,0870) \\
\end{array}$ \\
\hline \multirow{2}{*}{$\begin{array}{c}\text { Empleo } \\
\text { Cónyuge } \\
\text { (Ref.: No) }\end{array}$} & Sí & $\begin{array}{c}-0,750^{* * *} \\
(0,0513)\end{array}$ & $\begin{array}{c}-0,788^{* * * *} \\
(0,0514)\end{array}$ & $\begin{array}{c}-0,762 * * * \\
(0,0515)\end{array}$ & $\begin{array}{c}-0,755^{* * *} \\
(0,0514)\end{array}$ & $\begin{array}{c}-0,752 * * * \\
(0,0514)\end{array}$ \\
\hline & $\begin{array}{l}\text { No tiene } \\
\text { cónyuge }\end{array}$ & $\begin{array}{c}-0,573 * * * \\
(0,0789) \\
\end{array}$ & $\begin{array}{c}-0,591 * * * \\
(0,0789) \\
\end{array}$ & $\begin{array}{c}-0,579 * * * \\
(0,0787) \\
\end{array}$ & $\begin{array}{c}-0,572 * * * \\
(0,0788) \\
\end{array}$ & $\begin{array}{c}-0,573 * * * \\
(0,0787) \\
\end{array}$ \\
\hline \multirow{3}{*}{$\begin{array}{c}\text { Edad } \\
\text { (Ref.: De } 16 \text { a } \\
\text { 34) }\end{array}$} & Más de 60 & $\begin{array}{c}-0,438 * * * \\
(0,0851)\end{array}$ & $\begin{array}{c}-0,478^{* * * *} \\
(0,0851)\end{array}$ & $\begin{array}{c}-0,486^{* * * *} \\
(0,0852)\end{array}$ & $\begin{array}{c}-0,472 * * * \\
(0,0851) \\
\end{array}$ & $\begin{array}{c}-0,469^{* * * *} \\
(0,0850)\end{array}$ \\
\hline & De 44 a 59 & $\begin{array}{c}-0,502 * * * \\
(0,0712)\end{array}$ & $\begin{array}{c}-0,542 * * * \\
(0,0713)\end{array}$ & $\begin{array}{c}-0,538^{* * *} \\
(0,0713)\end{array}$ & $\begin{array}{c}-0,529 * * * \\
(0,0712)\end{array}$ & $\begin{array}{c}-0,526 * * * \\
(0,0712)\end{array}$ \\
\hline & De 35 a 44 & $\begin{array}{c}-0,292 * * * \\
(0,0733)\end{array}$ & $\begin{array}{c}-0,323 * * * \\
(0,0734)\end{array}$ & $\begin{array}{c}-0,314 * * * \\
(0,0733)\end{array}$ & $\begin{array}{c}-0,311 * * * \\
(0,0733)\end{array}$ & $\begin{array}{c}-0,306 * * * \\
(0,0732)\end{array}$ \\
\hline \multirow{2}{*}{$\begin{array}{c}\text { Estado civil } \\
\text { (Ref.: Casado) }\end{array}$} & $\begin{array}{l}\text { Soltero o } \\
\text { viudo }\end{array}$ & $\begin{array}{c}0,445^{* * *} \\
(0,0713)\end{array}$ & $\begin{array}{c}0,434 * * * \\
(0,0713)\end{array}$ & $\begin{array}{c}0,428 * * * \\
(0,0711)\end{array}$ & $\begin{array}{c}0,432 * * * \\
(0,0712)\end{array}$ & $\begin{array}{c}0,434 * * * \\
(0,0712)\end{array}$ \\
\hline & $\begin{array}{l}\text { Separado o } \\
\text { divorciado }\end{array}$ & $\begin{array}{c}0,628^{* * *} \\
(0,0872)\end{array}$ & $\begin{array}{c}0,614 * * * \\
(0,0874) \\
\end{array}$ & $\begin{array}{l}0,621 * * * \\
(0,0872) \\
\end{array}$ & $\begin{array}{l}0,617 * * * \\
(0,0873) \\
\end{array}$ & $\begin{array}{c}0,626^{* * * *} \\
(0,0871)\end{array}$ \\
\hline $\begin{array}{c}\text { Edad máxima } \\
\text { de estudios }\end{array}$ & & $\begin{array}{l}-0,008^{* *} \\
(0,0039)\end{array}$ & $\begin{array}{l}-0,009 * * \\
(0,0039) \\
\end{array}$ & $\begin{array}{l}-0,010^{* *} \\
(0,0039)\end{array}$ & $\begin{array}{c}-0,009 * * \\
(0,0039)\end{array}$ & $\begin{array}{c}-0,009 * * \\
(0,0039)\end{array}$ \\
\hline PIB & & $\begin{array}{c}-3,912 * * * \\
(0,8258)\end{array}$ & & & & \\
\hline Tasa de Paro & & & $\begin{array}{c}4,669 * * * \\
(0,4434)\end{array}$ & & & \\
\hline Deuda Pública & & & & $\begin{array}{c}0,971 * * * \\
(0,2760)\end{array}$ & & \\
\hline Crédito & & & & & $\begin{array}{l}-1,223^{*} \\
(0,6287) \\
\end{array}$ & \\
\hline Presión. Fiscal & & & & & & $\begin{array}{l}0,761 * * \\
(0,3041)\end{array}$ \\
\hline
\end{tabular}

Errores estándar entre paréntesis; $* * * \mathrm{p}<0,01,{ }^{* *} \mathrm{p}<0,05,{ }^{*} \mathrm{p}<0,1$.

Fuente: Elaboración propia. 
Atendiendo a los resultados mostrados en las tablas 12 y 13 se confirman las hipótesis de influencia de la carga regulatoria y la eficiencia de la justicia (hipótesis 15 y 17), pues su coeficiente resulta estadísticamente significativo en la parte de efectos fijos del modelo. Sin embargo, se rechaza la hipótesis en caso de la transparencia por falta de significatividad estadística (hipótesis 16), además de arrojar un coeficiente con sentido contrario al que se esperar. De esta forma, la probabilidad de fracasar de un empresario autónomo es mayor cuanto mayor sea la carga regulatoria de la Comunidad Autónoma en donde realiza su actividad, en relación con el total de normas de todas las Comunidades Autónomas y cuanto menor sea la eficiencia de los juzgados de lo mercantil en la tramitación de asuntos. En segundo lugar, el sector de actividad resulta significativo en la parte aleatoria de todos los modelos, lo que confirma la hipótesis de diferencias en la especialización sectorial de las regiones y en su influencia en la probabilidad de fracasar de los empresarios autónomos. Por último, también se debe destacar que la inclusión de las variables institucionales en la parte aleatoria del modelo no ha resultado significativa.

Tabla 12. Efectos fijos. Inclusión de variables institucionales

\begin{tabular}{|c|c|c|c|c|}
\hline Variable & Categoría & Modelo 6 & Modelo 7 & Modelo 8 \\
\hline Intersección & & $\begin{array}{c}-0,955^{* * *} * \\
(0,1469)\end{array}$ & $\begin{array}{c}-0,999 * * * \\
(0,2026)\end{array}$ & $\begin{array}{c}-0,539 * * * \\
(0,1660)\end{array}$ \\
\hline $\begin{array}{c}\text { Crea empleo } \\
\text { (referencia: No) }\end{array}$ & Sí & $\begin{array}{c}-1,160^{* * *} \\
(0,0570) \\
\end{array}$ & $\begin{array}{c}-1,159 * * * \\
(0,0570)\end{array}$ & $\begin{array}{c}-1,155^{* * * *} \\
(0,0570)\end{array}$ \\
\hline $\begin{array}{c}\text { Sexo } \\
\text { (referencia: } \text { Mujer) }\end{array}$ & Varón & $\begin{array}{c}-0,624 * * * \\
(0,0485)\end{array}$ & $\begin{array}{c}-0,624 * * * \\
(0,0485)\end{array}$ & $\begin{array}{c}-0,625 * * * \\
(0,0485)\end{array}$ \\
\hline \multirow{4}{*}{$\begin{array}{c}\text { Sector } \\
\text { (referencia: } \\
\text { Construcción) }\end{array}$} & $\begin{array}{l}\text { Resto de } \\
\text { servicios }\end{array}$ & $\begin{array}{c}-0,962 * * * \\
(0,0916)\end{array}$ & $\begin{array}{c}-0,965 * * * \\
(0,0915) \\
\end{array}$ & $\begin{array}{c}-0,967 * * * \\
(0,0915) \\
\end{array}$ \\
\hline & Primario & $\begin{array}{c}-1,492 * * * \\
(0,1193)\end{array}$ & $\begin{array}{c}-1,493 * * * \\
(0,1191)\end{array}$ & $\begin{array}{c}-1,493 * * * \\
(0,1191)\end{array}$ \\
\hline & Industria & $\begin{array}{c}-0,795^{* * *} \\
(0,1131)\end{array}$ & $\begin{array}{c}-0,795 * * * \\
(0,1130)\end{array}$ & $\begin{array}{c}-0,795 * * * \\
(0,1130)\end{array}$ \\
\hline & $\begin{array}{c}\text { Distribución } \\
\text { comercial }\end{array}$ & $\begin{array}{c}-0,559 * * * \\
(0,0874)\end{array}$ & $\begin{array}{c}-0,562 * * * \\
(0,0872)\end{array}$ & $\begin{array}{c}-0,564 * * * \\
(0,0872)\end{array}$ \\
\hline \multirow{2}{*}{$\begin{array}{l}\text { Empleo cónyuge } \\
\text { (referencia: No) }\end{array}$} & Sí & $\begin{array}{c}-0,745^{* * *} \\
(0,0513) \\
\end{array}$ & $\begin{array}{c}-0,749 * * * \\
(0,0514) \\
\end{array}$ & $\begin{array}{c}-0,755^{* * *} \\
(0,0514) \\
\end{array}$ \\
\hline & $\begin{array}{l}\text { No tiene } \\
\text { cónyuge }\end{array}$ & $\begin{array}{c}-0,571 * * * \\
(0,0788) \\
\end{array}$ & $\begin{array}{c}-0,572 * * * \\
(0,0788) \\
\end{array}$ & $\begin{array}{c}-0,574 * * * \\
(0,0787) \\
\end{array}$ \\
\hline \multirow{3}{*}{$\begin{array}{c}\text { Edad } \\
\text { (referencia: De 16 a 34) }\end{array}$} & Más de 60 & $\begin{array}{c}-0,462 * * * \\
(0,0849)\end{array}$ & $\begin{array}{c}-0,467 * * * \\
(0,0851)\end{array}$ & $\begin{array}{c}-0,480 * * * \\
(0,0852)\end{array}$ \\
\hline & De 44 a 59 & $\begin{array}{c}-0,518^{* * *} \\
(0,0711)\end{array}$ & $\begin{array}{c}-0,523 * * * \\
(0,0712)\end{array}$ & $\begin{array}{c}-0,533 * * * \\
(0,0713)\end{array}$ \\
\hline & De 35 a 44 & $\begin{array}{c}-0,301 * * * \\
(0,0732)\end{array}$ & $\begin{array}{c}-0,304 * * * \\
(0,0732)\end{array}$ & $\begin{array}{c}-0,312 * * * \\
(0,0733)\end{array}$ \\
\hline
\end{tabular}




\begin{tabular}{|c|c|c|c|c|}
\hline Variable & Categoría & Modelo 6 & Modelo 7 & Modelo 8 \\
\hline $\begin{array}{c}\text { Estado civil } \\
\text { (referencia: Casado) }\end{array}$ & $\begin{array}{c}\text { Soltero o } \\
\text { viudo }\end{array}$ & $\begin{array}{c}0,439 * * * \\
(0,0712)\end{array}$ & $\begin{array}{c}0,435^{* * *} \\
(0,0712)\end{array}$ & $\begin{array}{c}0,430 * * * \\
(0,0712)\end{array}$ \\
\cline { 2 - 5 } & $\begin{array}{c}\text { Separado o } \\
\text { divorciado }\end{array}$ & $\begin{array}{c}0,629 * * * \\
(0,0871)\end{array}$ & $\begin{array}{c}0,627 * * * \\
(0,0871)\end{array}$ & $\begin{array}{c}0,622^{* * *} \\
(0,0872)\end{array}$ \\
\hline $\begin{array}{c}\text { Edad máxima de } \\
\text { estudios }\end{array}$ & & $\begin{array}{c}-0,009 * * \\
(0,0039)\end{array}$ & $\begin{array}{c}-0,009 * * \\
(0,0039)\end{array}$ & $\begin{array}{c}-0,009 * * \\
(0,0039)\end{array}$ \\
\hline Carga regulatoria & & $\begin{array}{c}1,747 * \\
(0,9832)\end{array}$ & & \\
\hline Transparencia & & & 0,002 & \\
\hline \multirow{2}{*}{ Eficiencia justicia } & & & & $-0,0020)$ \\
& & & & $(0,0738 *)$ \\
\hline
\end{tabular}

Errores estándar entre paréntesis; *** $\mathrm{p}<0,01, * * \mathrm{p}<0,05, * \mathrm{p}<0,1$.

Fuente: Elaboración propia

Tabla 13: Parte aleatoria.

Inclusión de variables macroeconómicas e institucionales

\begin{tabular}{|c|c|c|c|c|c|c|c|c|}
\hline & Modelo & Modelo & Modelo & Modelo & Modelo & Modelo & Modelo & Modelo \\
$\mathbf{1}$ & $\mathbf{2}$ & $\mathbf{3}$ & $\mathbf{4}$ & $\mathbf{5}$ & $\mathbf{6}$ & $\mathbf{7}$ & $\mathbf{8}$ \\
\hline Var. & $0,045^{* *}$ & 0,020 & $0,040^{* *}$ & $0,046^{* *}$ & $0,042^{* *}$ & $0,041^{* *}$ & $0,045^{* *}$ & $0,046^{* *}$ \\
Constante & $(0,022)$ & $(0,015)$ & $(0,020)$ & $(0,023)$ & $(0,021)$ & $(0,020)$ & $(0,022)$ & $(0,022)$ \\
\hline Var. & $0,026^{* *}$ & $0,029^{* *}$ & $0,026^{* *}$ & $0,027^{* *}$ & $0,026^{* *}$ & $0,026^{* *}$ & $0,026^{* *}$ & $0,026^{* *}$ \\
Sector & $(0,012)$ & $(0,013)$ & $(0,012)$ & $(0,012)$ & $(0,012)$ & $(0,012)$ & $(0,012)$ & $(0,012)$ \\
\hline Var. & - & - & - & $4,361^{* *}$ & - & - & - & - \\
Crédito & - & - & - & $(2,375)$ & - & - & - & - \\
\hline
\end{tabular}

Errores estándar entre paréntesis; $* * * p<0,01,{ }^{* *} \mathrm{p}<0,05,{ }^{*} \mathrm{p}<0,1$.

Fuente: Elaboración propia

\section{DISCUSIÓN Y CONCLUSIONES}

El trabajo desarrollado partía de un objetivo claro: analizar la importancia de los empresarios autónomos en la economía española y los factores que inciden en la probabilidad de fracaso de los emprendedores autónomos españoles a doce meses, con especial atención a las causas de índole macroeconómica e institucional que pueden favorecer dicha probabilidad.

Con el fin de alcanzar dicho objetivo, en primer lugar, se ha analizado el peso de los autónomos en la estructura empresarial española, desarrollando para ello un perfil socioeconómico del empresariado autónomo y destacando las dificultades a las que se enfrenta en el desarrollo de la actividad. En segundo lugar, 
se ha analizado el fenómeno del fracaso empresarial, destacando la evolución de las tasas de mortalidad tanto para las empresas activas como para las de nueva constitución, encontrando diferencias a nivel de Comunidad Autónoma que justifican el análisis empírico desarrollado en el resto del trabajo.

Así pues, se ha partido de la información contenida en los microdatos de la Encuesta de Población Activa (EPA), que permiten disponer de datos a nivel hogar (incluyendo a todos los miembros del hogar) durante un amplio periodo de tiempo. Teniendo en cuenta las definiciones propias de la EPA, se ha considerado como empresario autónomo a toda aquella persona que realiza su actividad bajo esta denominación, independientemente de si contrata o no a otros trabajadores, siempre que haya desarrollado su actividad con un mínimo de doce meses, teniendo en cuenta si a la fecha de análisis ha abandonado su actividad y se encuentra en desempleo o mantiene en funcionamiento el negocio. Por lo tanto, no se han considerado aquellos casos en los que, habiendo abandonado la actividad, la persona se ha jubilado, se le ha reconocido una incapacidad o ha empezado a trabajar de nuevo, sino únicamente los que se encuentran en situación de búsqueda activa de empleo.

En lo que respecta a las variables utilizadas en la explicación del fenómeno del fracaso, se han considerado tres tipos de factores. En primer lugar, se han considerado las características socioeconómicas de los empresarios, que son las que impactan de una forma más directa en su capacidad de supervivencia. Estos factores son: la edad, el sexo, la edad a la que se alcanzó el máximo nivel de formación, el estado civil, el hecho de que el cónyuge (si lo tiene) tiene trabajo, si tiene familia con hijos o no, el sector de actividad o si emplea a otros trabajadores o no. Estas variables resultaron ser estadísticamente significativas, salvo en el caso del hecho de tener hijos o no, que, por lo tanto, no ha sido incluida en los modelos finales.

En segundo lugar, se han considerado variables de índole macroeconómica e institucional como factores explicativos de la propensión a fracasar de los emprendedores autónomos. Sin embargo, la principal aportación del trabajo está relacionada con la consideración de estos factores desde una perspectiva regional. La principal hipótesis es, por lo tanto, la existencia de diferencias a nivel regional en la probabilidad a fracasar, de forma que las condiciones macroeconómicas e institucionales de las Comunidades Autónomas tienen incidencia en dicha probabilidad. Para llevar a cabo la contrastación de esta hipótesis, se han aplicado modelos de regresión logística multinivel, en los que se diferencian dos partes: una basada en efectos fijos y otra parte aleatoria en la que se puede apreciar si existen diferencias entre las Comunidades Autónomas que lleven a diferentes probabilidades de fracaso sólo por motivos de la región. 
La utilización de los modelos multinivel ha permitido observar diferencias regionales a la hora de explicar la probabilidad de fracasar de los empresarios autónomos. De esta forma, se legitima la inclusión de las variables macroeconómicas e institucionales a nivel regional. En este sentido, las variables macroeconómicas estudiadas han sido: el crecimiento anual del PIB de cada Comunidad Autónoma, la tasa de paro autonómica, la deuda pública autonómica (como porcentaje del PIB), el crecimiento anual del crédito bancario en cada Comunidad Autónoma y la variación anual de la presión fiscal autonómica. Este último indicador se ha construido para este trabajo en base a los datos de los ingresos tributarios y las cotizaciones a la Seguridad Social. Finalmente, los análisis realizados han permitido concluir que todas las variables macroeconómicas examinadas son estadísticamente significativas. En lo que respecta a las variables institucionales, en primer lugar, se ha utilizado el índice de transparencia de las Comunidades Autónomas publicado por Transparencia Internacional España, resultando no significativo en el modelo. En segundo lugar, se han construido dos indicadores: por una parte, una variable representativa de la carga regulatoria autonómica de las empresas, en base a los datos de la CEOE sobre número de páginas de los boletines oficiales de las Comunidades Autónomas, resultando significativo el hecho de que, a mayor carga regulatoria, más probabilidad de fracasar. Por otro lado, se ha construido un indicador que busca reflejar la eficiencia de los juzgados de lo mercantil de cada Comunidad Autónoma en la tramitación de asuntos, resultando significativo que, a mayor ineficiencia de tramitación de asuntos, mayor probabilidad de fracasar. Finalmente, la especialización sectorial de las Comunidades Autónomas ha resultado ser significativa en la explicación de las diferencias de la propensión a fracasar a nivel regional.

Por lo tanto, como conclusión y aportación a la profunda discusión que requiere la mejora del entorno empresarial, los resultados muestran diferencias regionales e incidencia de factores macroeconómicos e institucionales en la propensión a fracasar de los empresarios autónomos españoles. Dado que los empresarios personas físicas son un segmento de vital importancia en la estructura productiva de España (53,5\% del total de empresas), las políticas económicas (y públicas en general) deberían orientarse a mejorar el entorno empresarial, tanto nacional como autonómico, en términos no sólo de crecimiento económico y pleno empleo, sino también en controlar la deuda pública y la presión fiscal, facilitar, en la medida de lo posible, el flujo de crédito a la economía real y, en términos más estructurales, mejorar la eficiencia de los juzgados en la tramitación de asuntos y moderar la carga regulatoria, estableciendo una menor regulación pero más eficaz y de mejor acceso y entendimiento por parte de los empresarios. 


\section{BIBLIOGRAFÍA}

- ACOSTA, E.; FERNÁNDEZ, F., y GANGA, H., "Predicting Corporate Financial Failure Using Macroeconomic Variables and Accounting Data", en Computational Economics, 1(53) (2019) 227-257.

- ALTMAN, E. I., "Financial Ratios, Discriminant Analysis and the Prediction of Corporate Bankruptcy", en The Journal of Finance, 23 Septiembre1968.

- ALTMAN, E. I., Corporate financial distress, Chinchester. John Wiley\&Sons, 1983.

- ÁlVAREZ, G., y OTERO, M. S., "Abandono de la actividad empresarial en España: un enfoque de género", en Revista Europea de Dirección y Economía de la Empresa, 15 (4) (2006) 69-86.

- ARDAGNA, S., y LUSARDI, A., Explaining International Differences in Entrepreneurship: The Role of Individual Characteristics and Regulatory Constraints. NBER Working Paper, 14012 (2008).

- ARMOUR, J., y CUMMING, D., "Bankruptcy law and entrepreneurship", en American Law and Economics Review, 10(2) (2008) 303-350.

- ARQUERO, J. L.; ABAD, M. C., y JMÉNEZ, S. M., "Procesos de fracaso empresarial en pymes: Identificación y contrastación empírica", en Revista Internacional de la Pequeña y Mediana Empresa, 1 (2) (2008) 64-77.

- BANCO MUNDIAL, Doing Business en España 2015. Recuperado de: http://espanol.doingbusiness.org/es/reports/subnational-reports/spain.

- BEAVER, W. H.; MCNICHOLS, M., y RHIE, J., "Have financial statements become less informative? Evidence from the ability of financial ratios to predict bankruptcy", en Review of Accounting Studies, 10 (1) (2005) 93-122.

- BEAVER, W. H.; CORREIA, M., y McNICHOLS, M., "Have changes in financial reporting attributes impaired informativeness? Evidence from the ability of financial ratios to predict bankruptcy", en Rock Center for Corporate Governance Working Paper, 13, Stanford University, 2009.

- BENITO, A.; DELGADO, F., y PAGES, J., "A synthetic indicator of financial pressure for Spanish firms". Documentos de trabajo Banco de España, 411, 2004). 
- BUEHLER, S.; KAISER, C., y JAEGER, F., "The geographic determinants of bankruptcy: evidence from Switzerland". en Small Business Economics, 39(1) (2012) 231-251.

- CARLING, K.; JACOBSON, T.; LINDÉ, J., y ROSZBACH, K., "Corporate credit risk modeling and the macro economy", en Journal of Banking and Finance, 31(3) (2007) 845-868.

- CEOE, La producción normativa en 2015, Madrid, CEOE, 2016.

- CEOE, La producción normativa en 2016, Madrid, CEOE, 2017.

- CEOE, La producción normativa en 2017, Madrid, CEOE, 2018.

- CHAVA, S. y JARROW, R. A. (2004): Bankruptcy prediction with industry effects. Review of Finance, 8(4), 537-569.

- CHEMIN, M., "The impact of the judiciary on entrepreneurship: Evaluation of Pakistan's Access to Justice Programme", en Journal of Public Economics, 93(1-2) (2009) 114-125.

- CONSEJO GENERAL DE ECONOMISTAS, Implicaciones económicas del funcionamiento de la justicia en España. Madrid, Consejo General de Economistas 2016.

- CONTRERAS, J. G., Análisis de quiebra empresarial: modelo de ecuaciones de estimación generalizadas sobre datos panel. Tesis doctoral de la Universidad Complutense de Madrid, 2016.

- DAVYDENKO, S. A., y FRANKS, J. R., "Do bankruptcy codes matter? A study of defaults in France, Germany, and the UK", en The Journal of Finance, 63(2) (2008) 565-608.

- DESAI, M.; GOMPERS, P., y LERNER, J., "Institutions, capital constraints and entrepreneurial firm dynamics: evidence from Europe", en Harvard NOM Working Paper, 03-59 (2005).

- GARCÍA-POSADA, M., y MORA-SANGUINETTI, J. S., "Entrepreneurship and enforcement institutions: Disaggregated evidence for Spain", en Documentos de Trabajo de Banco de España, 1405 (2014).

- GARRIDO, L.; REQUENA, M., y TOHARIA, L., "La Encuesta de Población Activa desde la perspectiva de los hogares", en Estadística Española, 42 (146) (2000) 115-152. 
- GARRIDO, R.; GALLO, M.T., y MARTÍNEZ, D., "La crisis económica y la geografía del tejido empresarial español: 2000-2013", en Revista de Estudios Regionales, 106 (2016) 165-195.

- HALIM, A.; AHMAD, H.; DAUD, S. N. M., y MARZUKI, A., "Macroeconomic determinants of corporate failures in Malaysia", en International Journal of Business and Management, 3(3) (2008) 3-10.

- HOL, S., "The influence of the business cycle on bankruptcy probability", en International transactions in operational research, 14(1) (2007) 75-90.

- JONES, S., y HENSHER, D. A., Predicting firm financial distress: A mixed logit model”, en The Accounting Review, 79(4) (2004) 1011-1038.

- LAFFARGA, J.; MARTÍN, J. L., y VÁZQUEZ, M. J., "El análisis de la solvencia de las instituciones nanvarias: propuesta de una metodología y aplicaciones a la banca española", en ESIC-Market, 48 (1985) 51-57.

- LEE, S. H.; PENG, M. W., y BARNEY, J. B., "Bankruptcy law and entrepreneurship development: A real options perspective", en Academy of Management Review, 32(1) (2007) 257-272.

- LEE, S. H.; YAMAKAWA, Y.; PENG, M. W., y BARNEY, J. B., "How do bankruptcy laws affect entrepreneurship development around the world?" en Journal of Business Venturing, 26(5) (2011) 505-520.

- LICHAND, G., y SOARES, R. R., "Access to Justice and Entrepreneurship: Evidence from Brazil's Special Civil Tribunals", en Institute for the Study of Labor (IZA) Discussion Papers 5917 (2011).

- LIU, J., "Macroeconomic determinants of corporate failures: evidence from the UK", en Applied Economics, 36(9) (2004) 939-945.

- MALO, M. A., "Nuevas formas de empleo: del empleo atípico a las plataformas digitales", en Papeles de Economía Española, 156 (2018) 146-158,

- MORA-SANGUINETTI, J. S., y SPRUK, R., "Industry VS Services: Do enforcement institutions matter for specialization patterns? Disaggregated evidence for Spain", en Documentos de Trabajo de Banco de España, 1812 (2014). 
- OHLSON, J. A., "Financial ratios and the probabilistic prediction of bankruptcy", en Journal of Accounting Research, 18 (1) (1980) 109-131.

- POZUELO, J.; LABATUT, G., y VERES, E. J., "Validez de la información financiera en los procesos de insolvencia", en Cuadernos de Economía y Dirección de la Empresa, 16(1), (Enero-Marzo 2013) 23-40.

- PUENTE, S., "Convergencia regional en España: 1980-2015”, en Boletín Económico de Banco de España, 3/2017.

- SALMAN, A. K.; FRIEDRICHS, Y. V., y SHUKUR, G., "The Determinants of Failure of Small Manufacturing Firms: Assessing the Macroeconomic Factors", en International Business Research, 4(3) (2011) 22-32.

- SOMOZA, A., "La consideración de factores cualitativos, macroeconómicos y sectoriales en los modelos de predicción de la solvencia empresarial", en Papeles de Economía Española, 89/90 (2001) 402-426.

- STEPHEN, F.; URBANO, D., y VAN HEMMEN, S., "The responsiveness of entrepreneurs to working time regulations", en Small Business Economics, 32(3) (2009) 259-276.

- TASCÓN, M. T., y CASTAÑO, F. J., "Variables y modelos para la identificación y predicción del fracaso empresarial: revisión de la investigación empírica reciente", en $R C$-SAR, 1 (15) (2012) 7-58.

- TRANSPARENCIA INTERNACIONAL ESPAÑA, Índice de transparencia de las Comunidades Autónomas 2016, Recuperado de:

https://transparencia.org.es/indice-de-las-comunidades-autonomas-incau/ 
